\title{
قيم التخخل المهني للخدمة الاجتماعية في إدارة الكوارث
}

\section{Professional Intervention Values of Social Work in Managing Disasters}

إعداد

$$
\text { دكتور / عماد فاروق صالح }
$$

الأستاذ المساعد بقسم علم الاجتماع و العمل الاجتماعي - جامعة السلطان قابوس - سلطنة عمان

$$
\text { و أستاذ المجالات بكلية الخدمة الاجتماعية - جامعة الفيوم - مصر الهر }
$$

\section{دكتور / مجدي محمل مصطفي عبد ربها}

الأستاذ المساعد بقسم علم الاجتماع و العمل الاجتماعي - جامعة السلطان قابوس - سلطنة عمان

\section{الملخص العزبي}

اهتم البحث الحالي بمعالجة أحد الموضوعات المهمة المتعلقة بالتدخل المهني للخدمة الاجتماعية في إدارة الكوارث الطبيعية، ومن ثم سعى إلى تسليط الضوء على تاريخ التخخلات المهنية للخدمة الاجتماعية

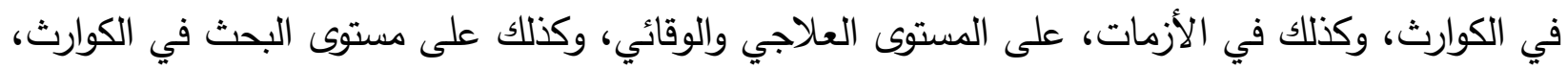

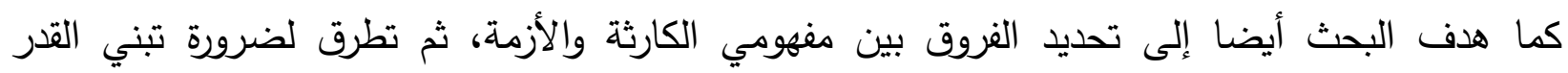
المناسب من الحساسية في أثناء الاسترشاد بالقيم المهنية، عند تقديم المساعدة للمنكوبين والمتضررين، جراء الكوارث الطبيعية. وقد نُِّْن البحث من خلا تبني المنهج الوصفي التحليلي الذي طُبِّقَ باتباع طريقة تحليل المضمون لبعض الدراسات الوثائقيـة للعديد من الدراسات المنشورة على المستوى العالمي.

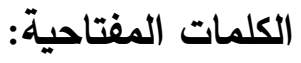
الكوارث الطبيعية - الأزمات - التخخل المهني - الخدمة الاجتماعية - القيم. 


\section{English Abstract}

The current research focused on addressing one of the important issues related to the professional intervention of the social work in natural disasters management, and then sought to shed light on the history of professional interventions in disasters as well as in crises, at both treatment and preventive levels.

In addition to research disasters. as the research also intended to identify the differences between the concepts of disaster and crisis, and then impressed on the need to adopt the appropriate amount of sensitivity while guiding professional values when providing assistance to those afflicted and affected by natural disasters.

The research was carried out by adopting the descriptive analytical Approach that was applied by following the content analysis method for some documentary studies (Documentary Approach), where many of these studies had been published on the global level.

\section{Keywords:}

Neutral Disasters - Crisis - Professional intervention - Social Work Values

أولا: مقدمة البحث وإثكاليته

يعاني العديد من المجتمعات الإنسانية من الآثار المدمرة التي تخلفها الكوارث الطبيعية وغير الطبيعية

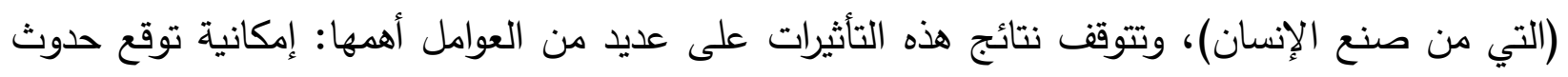

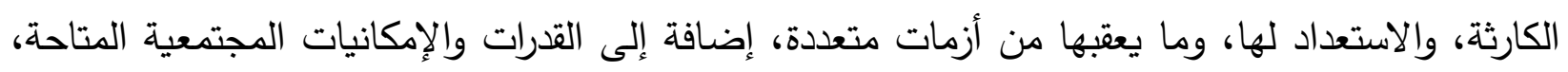

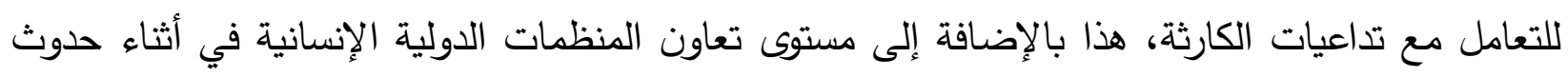

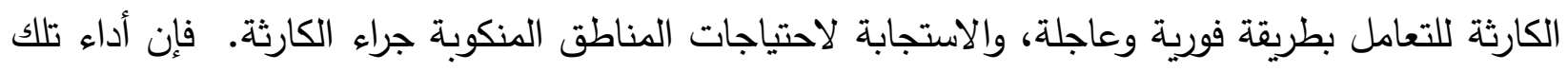

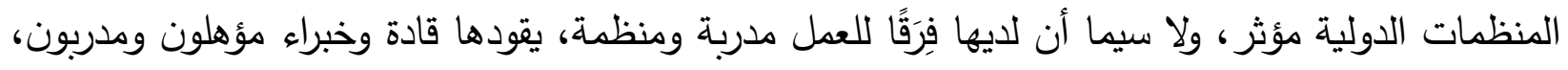

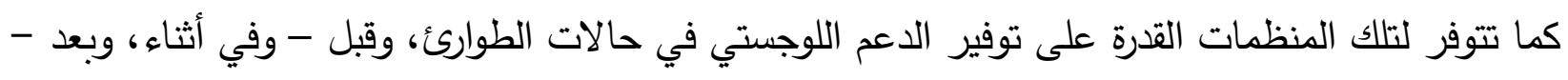
حدوث الكارثة في كثير من الأحيان.

أما عن الإحصائيات المتعلقة بالآثار المدمرة للكوارث الطبيعية، فيشير كل من "Ritchie \& Roser 2020"

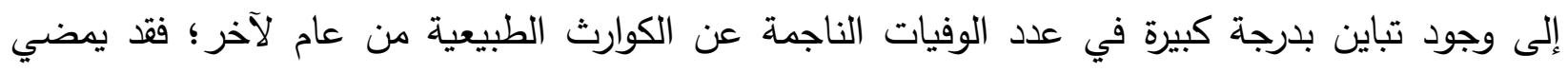

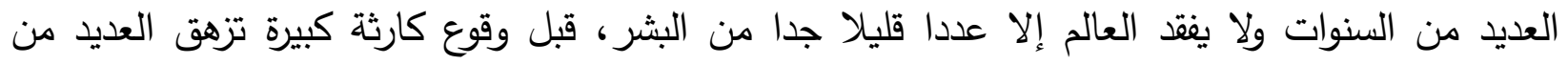

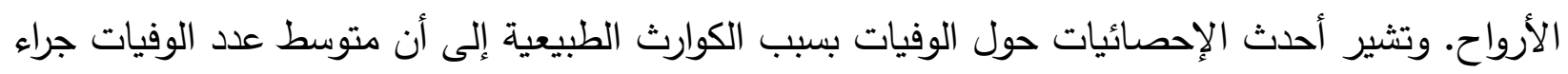


هذه النوعية من الكوارث، على مدى العقد الماضي، قارب 60.000 شخص على مستوى العالم كل عام، وهذا يمثل نسبة 0.1 \% من الوفيات العالمية. (Ritchie \& Roser , 2020) والثكل التالي رقم 1 الذي يتعلق بالوفيات نتيجة الكوارث الطبيعة على المستوى العالمي يؤكد ذلك التباين من فترة زمنية إلى أخرى (1900 إلى 2018)، حيث يشير الرقم المطلق إلى عدد الوفيات عالميا، جراء الكوارث الطبيعية - كل الكوارث الطبيعية - التي تثمل: الجفاف، والفيضانات، والطقس القاسي، ودرجة الحرارة القاسية، والانهيارات الأرضية، وحركات الجفاف المتعددة، وحرائق الجفاف، والنشاط البركاني، والزلازل

.(EMDAT, 2019)

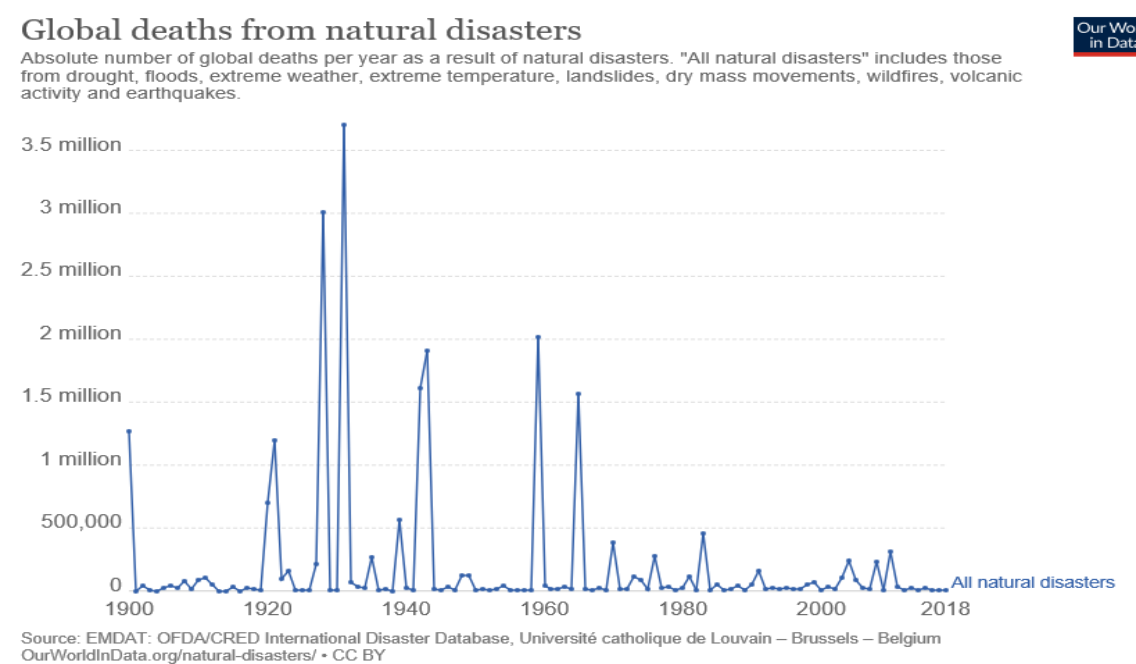

\section{Figure 1 Global deaths from natural disasters}

كذلك تؤدي الكوارث بأنواعها المختلفة إلى الدمار والخسائر، اللذين بدورهما يؤثران في جوانب متعددة

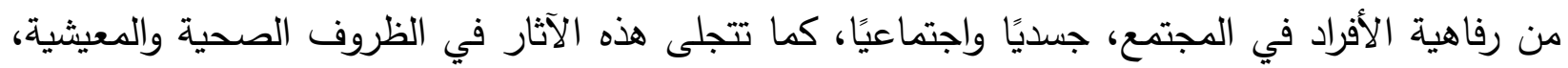

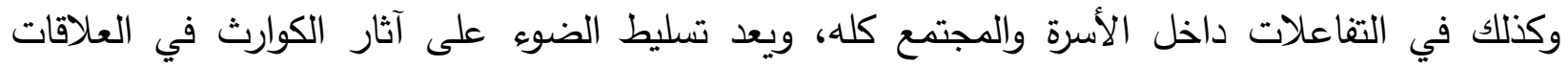
الاجتماعية من الأمور الحيوية، ليس من أجل الكثف عن جوانب الضعف وأنماطه فحسب، بل لفه لفهم قدرات أفراد المجتمع بثكل أفضل؛ كي يتم استثمارها في التعافي من آثار الصدمات والضغون الضوط. كما تؤدي الكوارث

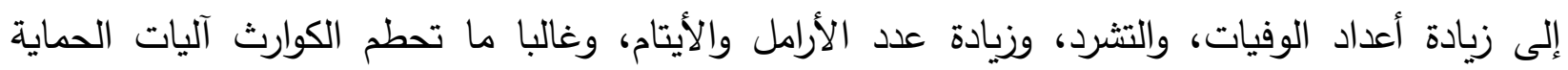

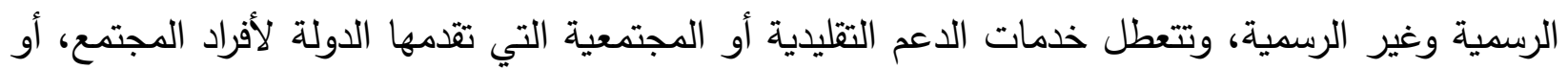

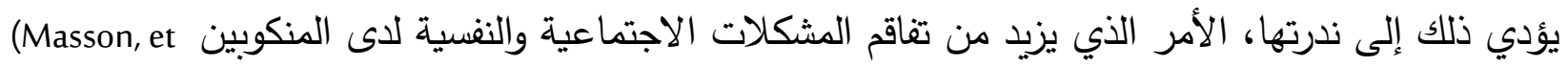

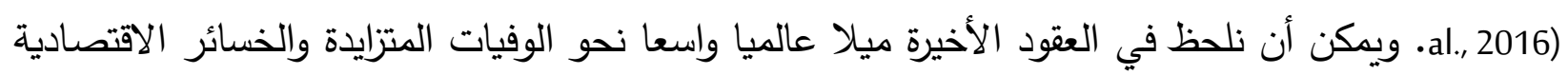
بسبب الأخطار الطبيعية، أو بسبب تلك التي تكون من صنع الإنسان، في جميع أنحاء العالم، ويمثل التوسع 
الحضري أحد أهم العوامل المؤثرة في هذه الزيادة في الخسائر والأهم من ذلك المستوطنات المعرضة بشكل خاص لتنامي الأزمات والفوضى الاجتماعية والاضطرابات السياسية والكوارث الطبيعية والكوارث التي من من لهن صنع الإنسان، بسبب الكثافة السكانية العالية والتطور السريع (Nojavan, et al., 2018) كما تزداد التأثيرات السلبية للكوارث على البيئة الاجتماعية المباشرة للأفراد، تلك البيئة التي تتألف من شبكات الدعم الاجتماعي بما فيها من العائلة، والأصدقاء، ومنظمات الخدمات الاجتماعية الرسمية، وغالبًا ما تتعطل هذه الشبكات بسبب الكوارث ذات النطاق الإقليمي؛ لذا تعد إعادة تشكيل تلك الشبكات للاعم الاجتماعي؛ أحد الأهداف الأساسية أمام برامج الإغاثة من الكوارث التي تستخدم المتطوعين، ويهدف ذلك إلى تقليل اضطراب الأداء الاجتماعي، وتيسير تعافي المتضررين من الكارثة. ومن ثم يبرز دور مهنة

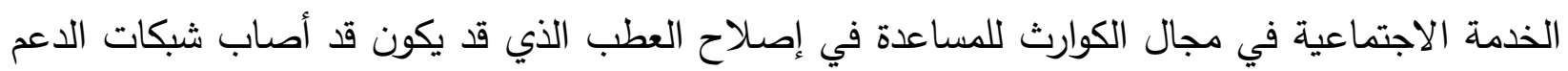

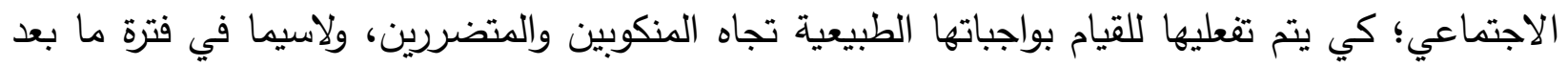
الكارثة. فلا يقتصر دور الخذمة الاجتماعية على الخبرة في تقديم الخدمات فقط، بل يتسع ليشمل كذلك

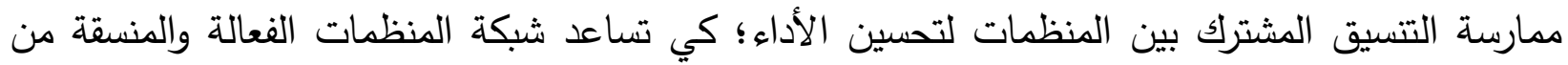
منظمات تقديم خدمات الكوارث الأفراد والأسر والمجتمعات على التعافي وتجنب المشاكل النفسية والاجتماعية طويلة المدى (Zakour, 1996).

ومن خلال استعراض العديد من الأدبيات النظرية العربية بالمتعلقة بإدارة الكوارث والأزمات وجدنا خطا واضحا، وتداخلا في الطرح والتتاول المنهي، بين دور الخدمة الاجتماعية في إدارة الكوارث، وتدخلها

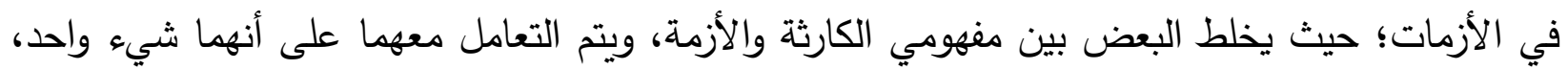
على الرغم من الاختلافات الثديدة بينهما. وقد سعينا من خلال البحث الحالي إلى إضافة شيء، وإن كان

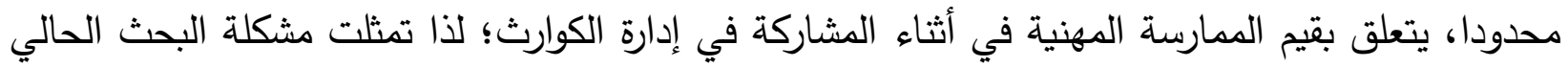
في معالجة أحد الموضوعات المهمة المتعلقة بالتدخل المهني للخدمة الاجتماعية في إدارة الكوارث الطبيعية

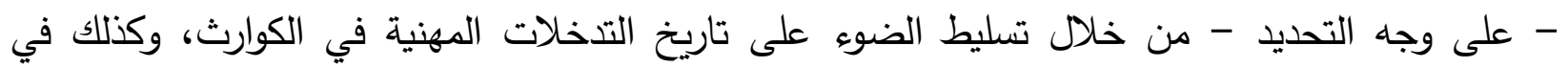

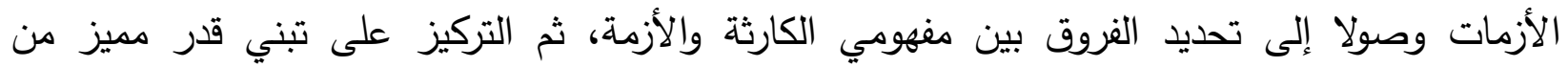
الحساسية في أثناء الاسترشاد بالقيم المهنية، عند تقديم المساعدة للمنكوبين والمتضررين، أفرادا وأسرا، جراء لهاء الكوارث الطبيعية. 
هدف البحث الحالي إلى استخلاص الدور التاريخي لمهنة الخدمة الاجتماعية في التنخل لإدارة آثار

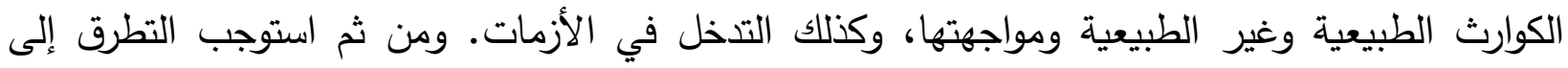
تحديد الفروق بين الكوارث الطبيعية والكوارث التي من صنع الإنسان والأزمات. كما سعى أيضا إلى تسليط

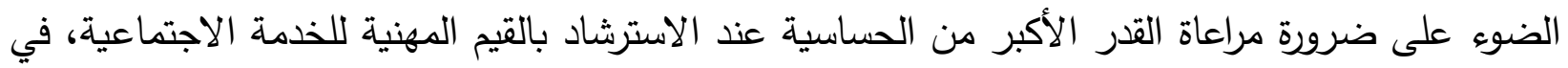
أثثاء التدخل المهني لتقديم الدعم والمساعدة الاجتماعية والنفسية والمادية للأفراد المنكوبين والمتضررين وأسرهم، جراء التعرض للكوارث الطبيعية.

ثالثا: تساؤلات البحث

في إطار السعي لتحقيق هذه الأهداف، وفي ضوئها، تحددت تساؤلاته في التالي :

1. ما الدور التاريخي لمهنة الخدمة الاجتماعية في التدخل لإدارة آثار الكوارث الطبيعية أو تلك التي

$$
\begin{aligned}
& \text { تكون من صنع الإنسان ومواجهتها، وكذلك التدخل في الأزمات؟ } \\
& \text { 2. ما المقصود بالكوارث الطبيعة والكوارث البشرية والأزمات؟ }
\end{aligned}
$$

3. ما مستوى حساسية الالتزام بتطبيق القيم المهنية للخدمة الاجتماعية في أثناء التخخل لمساعدة

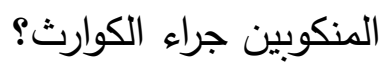

\section{رابعا: الاستراتيجية المنهجية}

عد هذا البحث من البحوث المرجعية التي حاولت تتبع الدور التاريخي لمهنة الخدمة الاجتماعية في التتخل في الكوارث والأزمات، وذلك من خـلال الاطـلاع على بعض الدراسات العلمية والاستفادة من أهم نتائجها للوصول إلى الأهداف التي حددها البحث وسعى إلى تحقيقها. وقد تم تتفيذ البحث من خلاد تبني المنهج الوصفي التحليلي الذي تم تطبيقه باتباع طريقة تحليل المضمون لبعض الدراسات الوثائقية

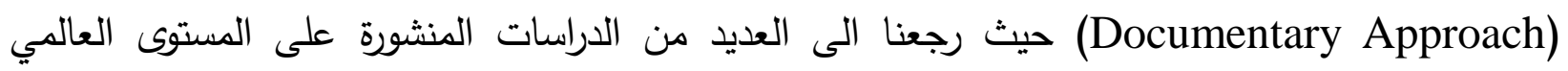
وجميعها مجلات مفهرسة ومصنفة ضمن Google Scholar.

\section{خامسا: الفرق بين الكارثة والأزمة}

على الرغم من الاتفاق بين الكارثة والأزمة (Disaster \& Crisis) في تداعياتهما الخطيرة وآثارهما

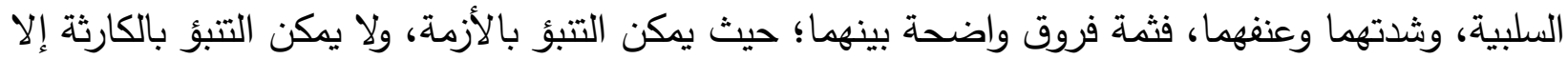

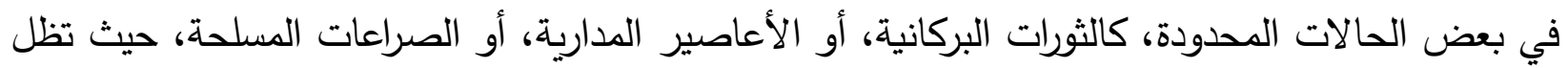

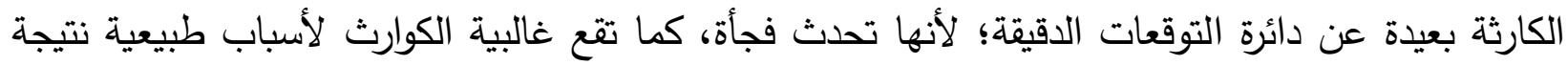


ثورات الطبيعية وتقلباتها، في حين أن أغلب الأزمات تتتج من أخطاء بشرية عمدية، أو نتيجة الإهمال. ولا

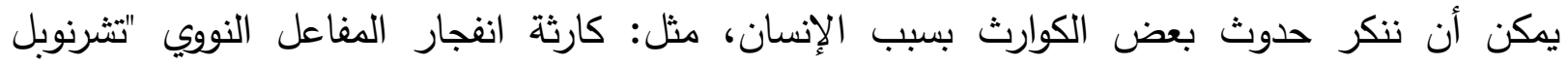
Chernobyl

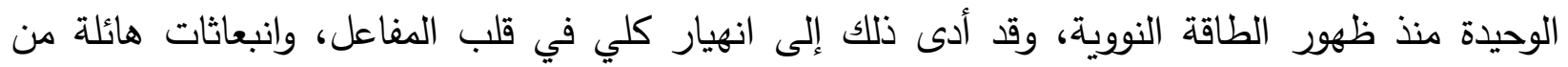
النويدات المشعة، ووفيات مبكرة لـ 31 شخصًا فقط، بالإضافة إلى العديد من التأثيرات السياسية،

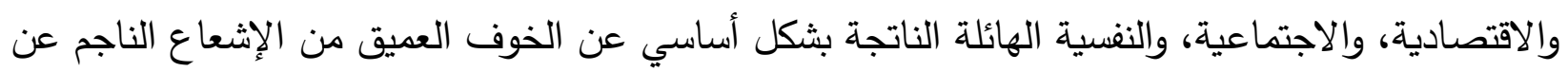

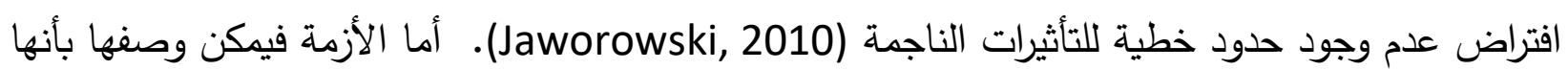
حالة داخلية من العجز العاطفي الناتج عن مشكلة، لا يمكن للفرد معالجتها بفعالية وفق تجاربه وخبراته

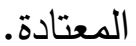

ووفق نظرية الأنساق، ينظر إلى الأزمة بوصفها اضطرابًا في التوازن أو في الحالة المستقرة التي

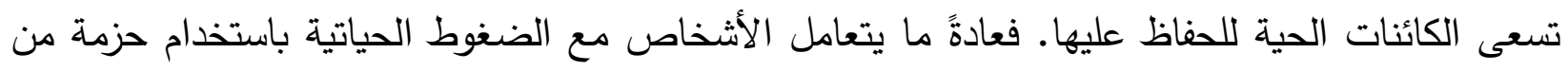

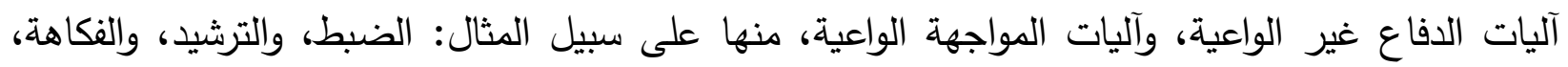

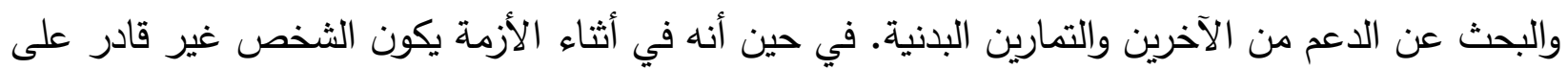

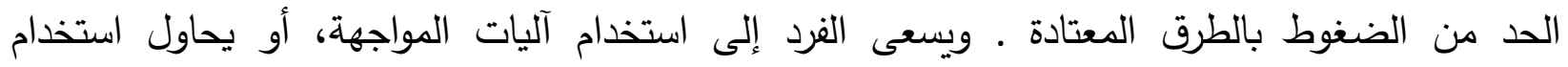

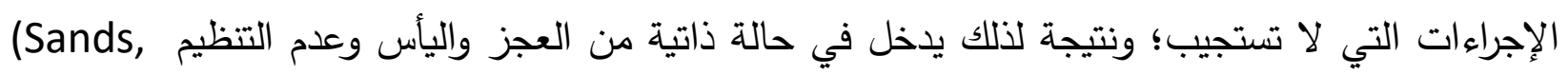

.Fall 1983, pp. 253-254)

ويمكن تصنيف معظم الكوارث الطبيعية التي تحدث بثكل متكرر إلي أربع فئات رئيسة: الفيضانات، والزلازل، والأعاصير، والمجاعات. كما أن هناك أحداثا كارثية أخرى، مثل: الانهيارات الأرضية،

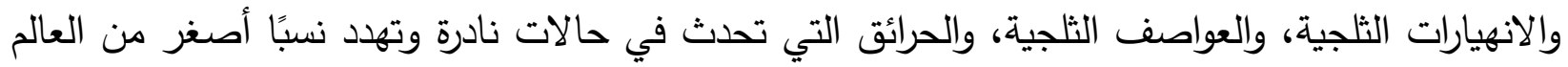
المكتظ بالسكان. وتعتبر الرياح والمياه والقوة التكتونية (هي نظرية علمية تصف الحركات الكبرى لغلاف الأرض الصخري أي القوى الخارجية التي تتشأ تحت السطح، والتي تغير التكوين السطحي للأرض نتيجة

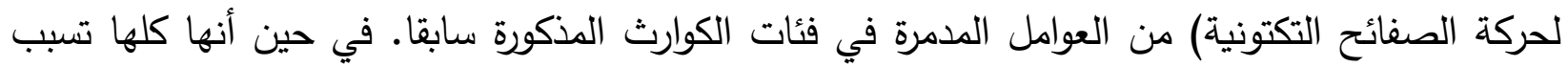
أضرارًا هيكلية، تختلف آثارها ما بين الوفيات والاعتلال على مدار الزمن (Guha-Sapir \& Lechat,

ولمزيد من التفصيل أشار الموقع الإلكتروني للاتحاد الدولي لجمعيات الصليب الأحمر والهلا The International Federation of Red Cross and Red Crescent Societies " الأحمر 
Center for research on the Epidemiology of " نقلا عن مركز بحوث علم الأوبئة - "(IFRC) disasters" - إلى أن المخاطر الطبيعية تحدث بشكل طبيعي ظواهر فيزيائية ناتجة إما عن أحداث سريعة

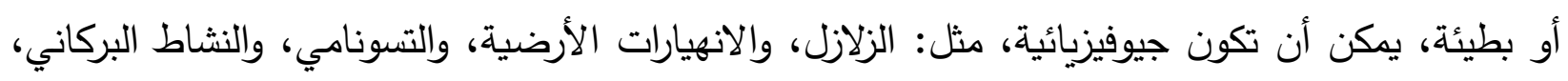

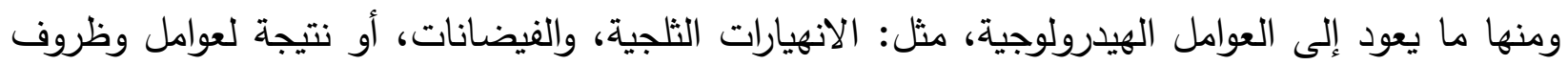

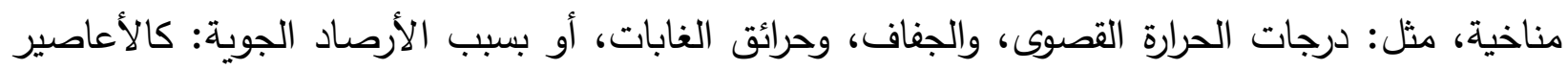

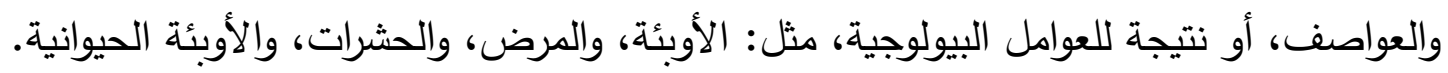

وتؤدي الكوارث الطبيعية مثل : الأعاصير والزلازل إلى وجود شعور بالعجز وعدم القدرة على التحكم

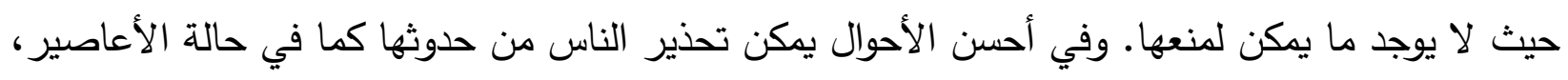

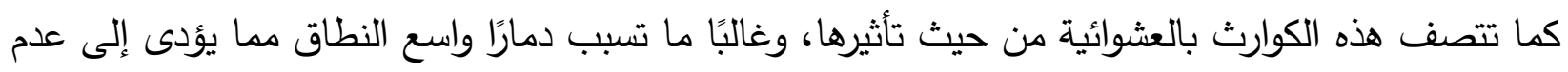

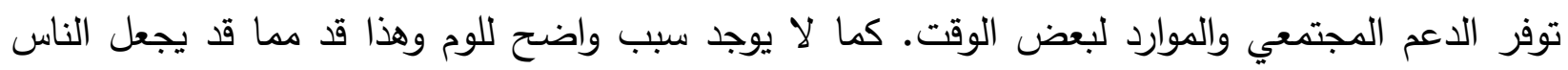
غاضبين من الطبيعة.(Becker, et al., 2008, pp. 3-4) مورئ

أما المخاطر التكنولوجية أو التي من صنع الإنسان، فتتمثل في: حالات الطوارئ، والنزاعات المعقدة،

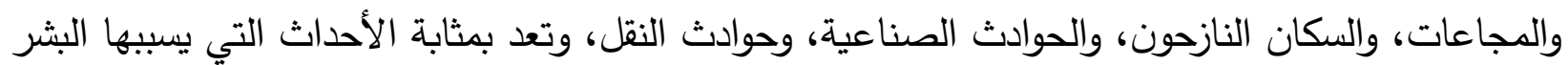

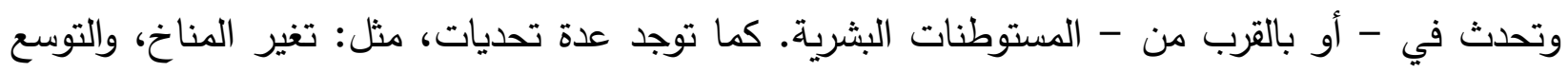
الحضري غير المخطط له، والتخلف، والفقر، وكذلك انتشار الأوبئة التي ستتطلب المساعدة الإنسانية في المستقبل؛ ومن ثم فإن كل هذه العوامل ستؤدي إلى زيادة تواتر الكوارث وتعقيدها وشدتها (IFRC, 2020). كذلك في الكوارث التي من صنع الإنسان كما هو الحال في أي هجوم إرهابي عادة ما تكون غير

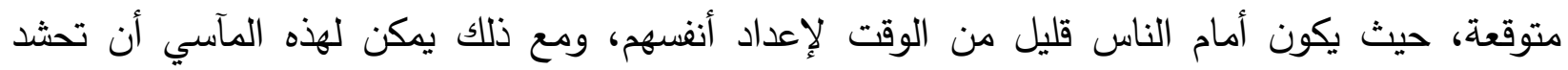

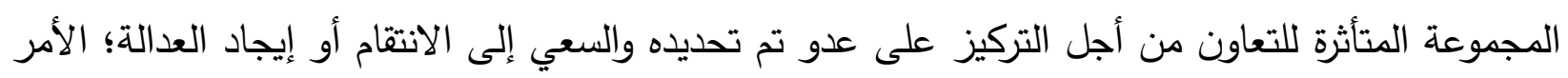

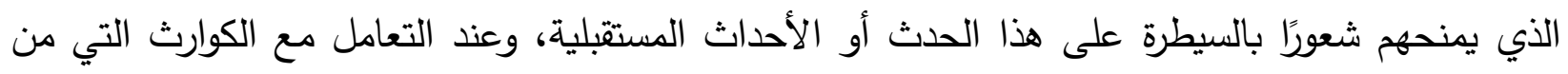

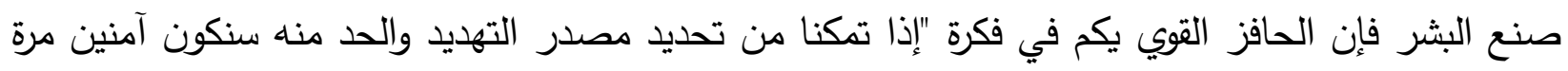
أخرى" (Becker, et al., 2008, p. 4)

وفى ضوء ما سبق يمكن ملاحظة وجود العديد من الفروق الواضحة بين الأزمة والكارثة، فالأزمة

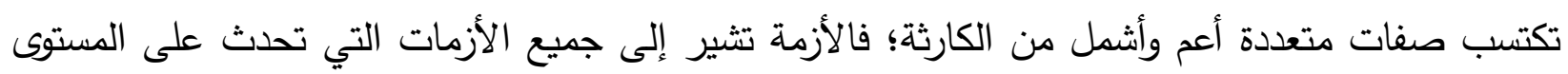
الفردي أو الأسري أو الجماعي أو المجتمي (المجتمعات المحلية - الإقليمية - الدولية)، أما الكارثة فتحصر في الحوادث ذات الخسائر الفادحة في الأرواح والممتلكات التي تحدث غالبا بشكل مفاجئ، ودون 
توقع أو استعداد لمواجهتها. وتتسم الأزمات وبعض أنواع الكوارث كالصراعات المسلحة بوجود مؤيدين

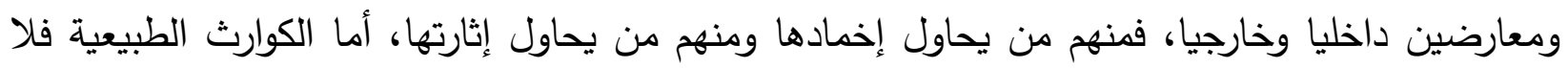
يوجد مؤيدون لها، بل تتسارع جميع الدول والجهات لتقديم العون المادي والمعنوي لمن أصابتهم الكارثة.

سادسا: نشأة الممارسة المهنية والبحثية وتطورها في مجال إدارة الكوارث الطبيعية والأزمات تعددت الآراء المهنية المتعلقة برصد الدور التاريخي لمهنة الخدمة الاجتماعية في التتخل لإدارة آثار

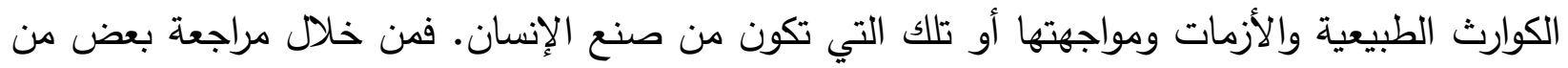

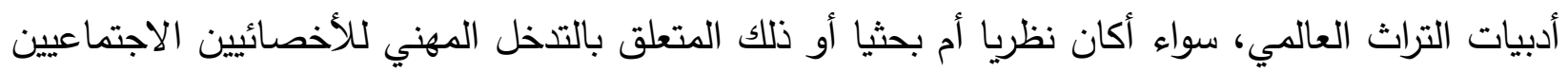

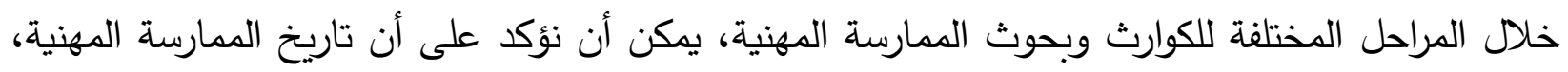

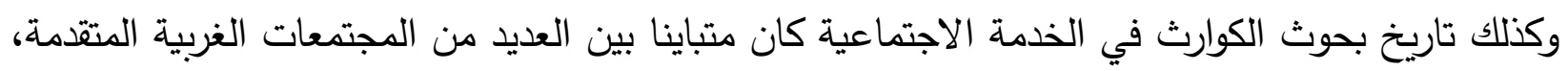
بما فيها الولايات المتحدة الأمريكية، والمجتمعات الثرقية، بما فيها الدول العربية والأسيوية بكافة مستوياتها.

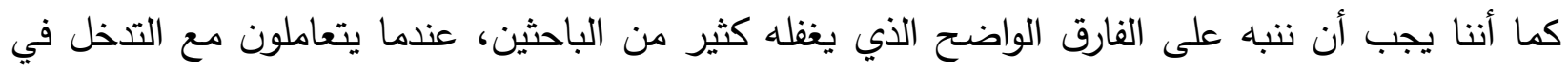

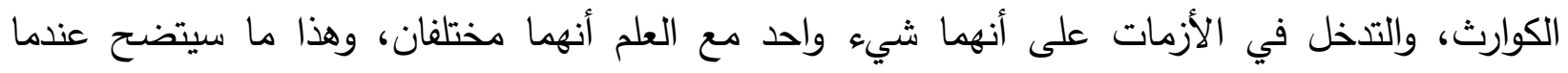

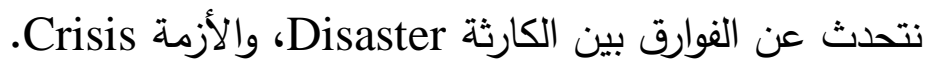

\section{مهنة الخدمة الاجتماعية وإلكوارث :}

لم يتضمن التراث النظري للخدمة الاجتماعية - حتى منتصف السبعينات من القرن الماضي -

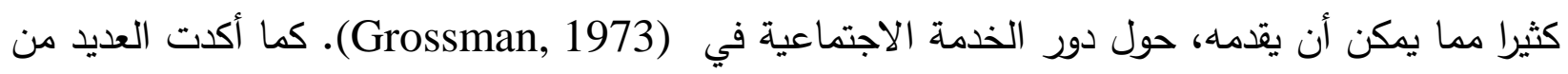
الكتابات النظرية، والدراسات الميدانية، في كثير من الدول الأسيوية؛ عدم وضوح الحاجة الملحة للتخخل

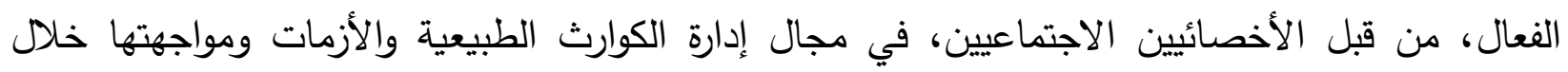
العقود الماضية؛ فقد كان تركيز الممارسة المهنية منصبا على مجموعة من مجالات الممارسة التقليدية

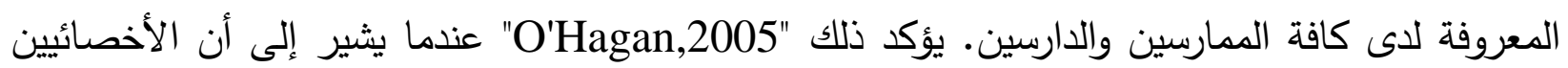
الاجتماعيين أطلقوا العنان لتخخلاتهم المهنية في العديد من المواقف والحالات، منها حالات: الإساءة للأطفال، وإضرابات المسنين، ومرضى الأمراض المزمنة، والفقد، والمرض العقلي، والنساء اللاتي بلغن سن النس

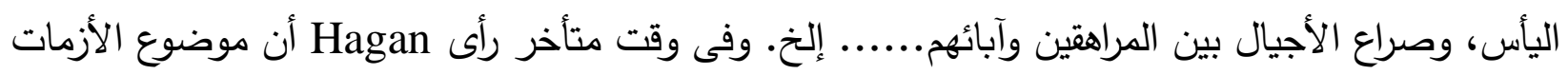

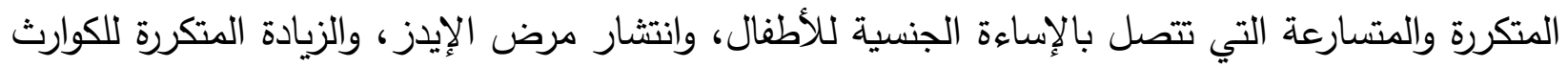

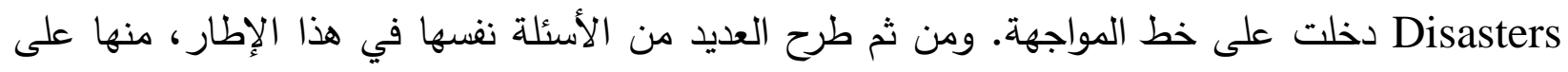
سبيل المثال: كيف يتعامل الأخصائيون الاجتماعيون مع هذه الكوارث؟ وكيف يمكن توفير التدريب الفعال 
(O'Hagan , لهم في هذا الموضوع؟ وما الأطر النظرية والمفاهيمية التي يمكن أن تدعم ممارستهم المهنية؟ .2005, p. 138)

وفي المقابل نجد فريقا آخر يري - دون شك - أن للخدمة الاجتماعية تاريخًا طويلًا في تلبية احتياجات الفئات المهشة من السكان، و ومنهم أولئك الذين يعانون من آثار الكوارث الطبيعية أو الكوارث التي تكون من صنع الإنسان، فعلى مدار التاريخ شاركت مهنة الخدمة الاجتماعية في عمليات الإغاثة في حالات الكوارث، وقد أولت آنذاك اهتماما كبيرا بالتدخلات النفسية والاجتماعية، في حين كان اهتمامها أقل

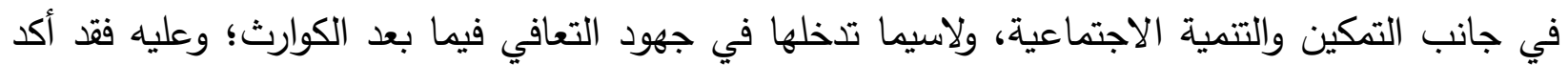

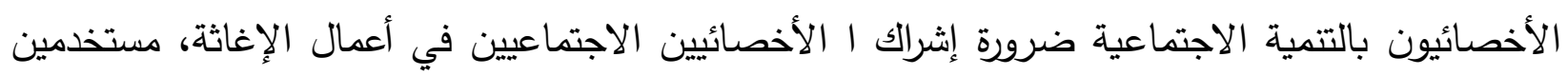

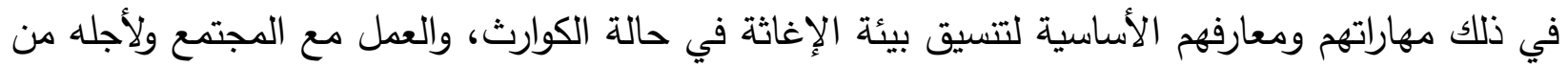
أجل تأمين وصول الموارد المجتمعية للأسر الضعيفة.

وأكدت "Nikku" كذلك عدم معرفة الكثير عن إسهام مهنة الخدمة الاجتماعية في كثير من الكوارث، منها على سبيل المثال: زلزال Bhuj 1993 في الهند، وزلزال تايوان عام 1999، وزلزال Kashmir في الهند؛ و تسونامي الآسيوي Asian Tsunami في 2004 في إندونيسيا، وزلزال 2001

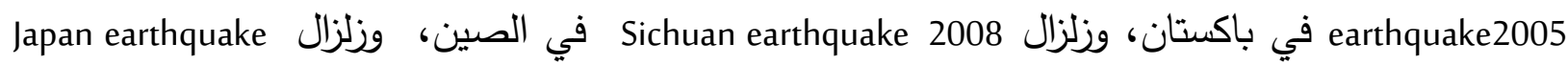
2011، وزلزال نيبال Nepal Earthquake 2015 وأن عدم المعرفة هذه لا يجب أن يفسر على أنه متمثل في عدم استجابة الأخصائيين الأكاديميين والممارسين لهذه الكوارث على أرض الواقع. فعلى الرغم من مشاركتهم في مواجهة آثار هذه الزلازل فإنهم لم يتمكنوا من الكتابة والنشر حول دور مهنة الخدمة الاجتماعية في

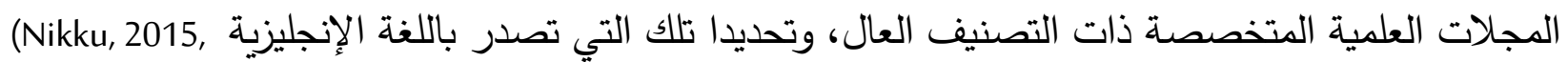
•pp. 601-602)

لذا فإنه بالرغم من استمرارية حدوث الكوارث سواء أكانت طبيعية أم من صنع الإنسان؟ فإن

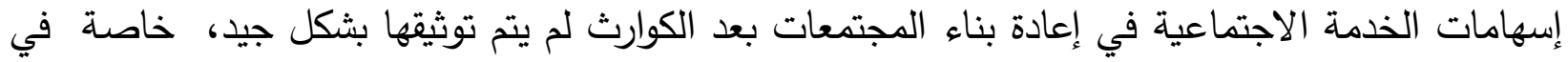

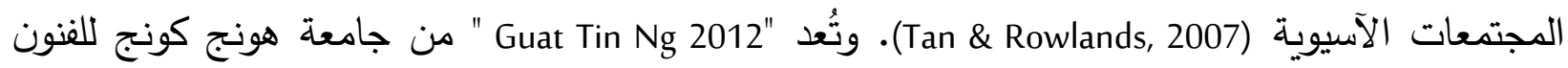
التطبيقية استثناءً في ذلك، حيث اهتمت بالنشر عن كفاءات الجهود المهنية للخدمة الاجتماعية ودورها في الإغاثة في حالة الكوارث، فمن خلال عملها ساعدت على دعم مستوى قبول الخدمة الاجتماعية في الصين في أثناء الكوارث الطبيعية، ولاسيما في بعض المهام التي ينظر إليها على أنها خدمة اجتماعية مهنية، كتقديم المشورة بشأن المنكوبين. 
وبالمثل طالب الأخصائيون الاجتماعيون بتعليم الخدمة الاجتماعية في كثير من الدول الأخرى

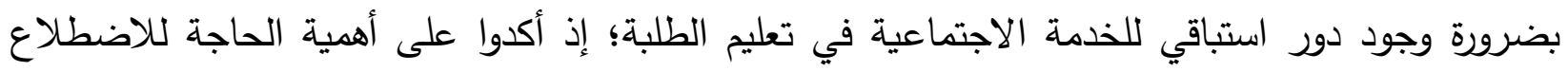

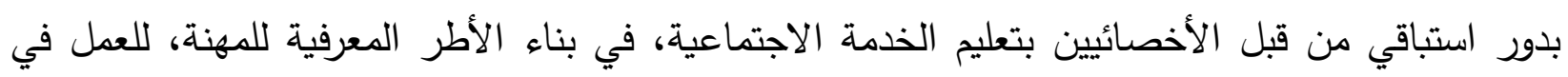

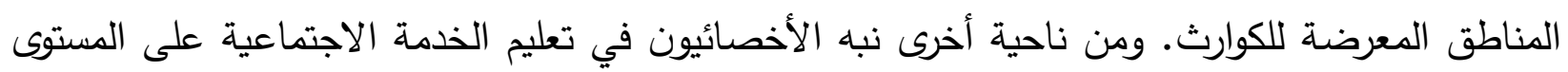

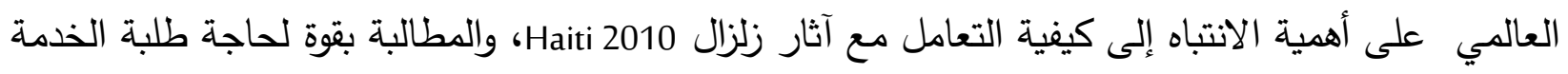

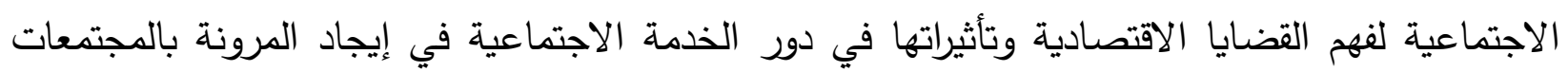
المحلية (Nikku, 2015, p. 602). وعلى الجانب الآخر، فإن المتتبع للتاريخ المهني للخدمة الاجتماعية في الدول الغربية؛ يستتنج أن للمهنة جهودًا بحثية متميزة في مجال الكوارث الاخر، وان والأزمات. لقد شاركت مهنة الخدمة الاجتماعية منذ فترة طويلة في الاستجابة للكوارث، وتطورت بحوث الكوارث في الخدمة الاجتماعية من خلال الدراسات الاجتماعية والنفسية للكوارث، كما يتوافق المفهوم المهني للكوارث الاثله والاهتمامات الرئيسة لبحوث الكوارث في الخدمة الاجتماعية؛ مع الرؤى النظرية للمهنة، ومهمتها التاريخية.

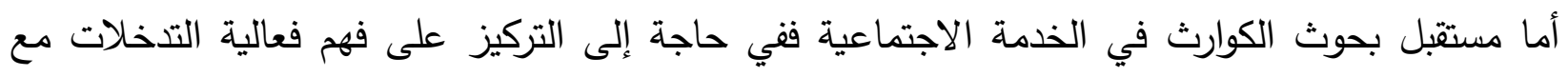
الكوارث، متضمنا الاستتاجات النفسية التي تخص الفئات الضعيفة - تحديدا - والمجتمعات المحلية التي تتنمي إلى الثقافات والأمم الأخرى.

كما يجب أن يأخذ مديرو الطوارئ في الاعتبار ، الاقتراحات المقدمة من بحوث الخدمة الاجتماعية، تلك التي تتضمن: الاهتمام - بعناية - بتكوين مجموعات استخلاص المعلومات، وإدماج الممارسات الدينية

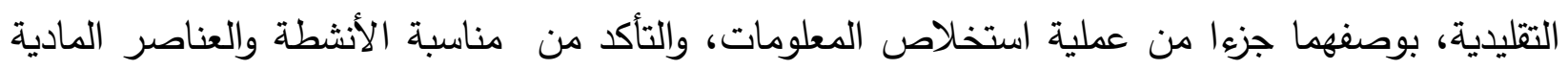
ثقافيا لمعسكرات اللاجئين، واعتماد توصيل الخدمات للمنظمات المستجيبة للكوارث، على نطاق جغرافي واسع، وتثجيع أنشطة التدريب المشتركة، وتبادل نظم المعلومات الجغرافية، وغيرها من التقنيات لتحسين التتسيق، والحرص على تجنيد المتطوعين في الكوارث، وتدريبه، والاحتفاظ بهم، وبناء تحالفات مجتمعية للمساعدة في تتسيق تقديم الخدمات في الكوارث.

وتعد هذه المقترحات متصلة - بدرجة كبيرة - من أجل بناء الثبكات الاجتماعية، بما فيها الثبكات

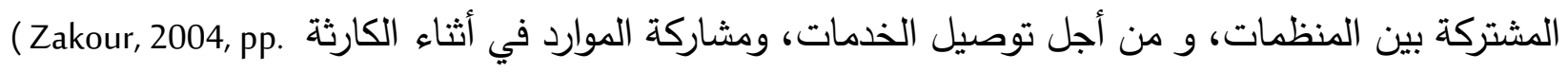

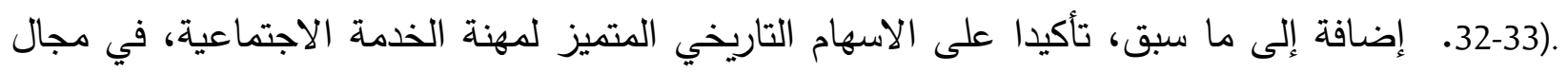
الكوارث والأزمات - سواء أكان على مستوى البحث أم الممارسة والتتخلات المهنية للأخصائيين الاجتماعيين - فيمكن الاستشهاد كذلك في هذا السياق ببعض ما تم نشره حول ذلك. 
وقد أكد "Zakour 1997" في إحدى مقالاته المنشورة، أن لبحوث الكوارث في تاريخ مهنة الخدمة الاجتماعية جذورا عميقة في مجال الإغاثة؛ إذ تمثلت مهمة الخدمة الاجتماعية في إيجاد الموارد، وجعلها في متتاول الناس، وتقديم الخدمات للسكان المنكوبين. كما كان للأخصائيين الاجتماعيين إسهامات مهمة، وفريدة من نوعها، لتنفيذها في بحوث الكوارث، عبر خبراتهم في المداخل البيئية، والوقائية، والتكيُفية، وتعزيز التغيير في الأنساق الصغيرة والكبيرة Micro and Macro Systems. ويجب أن ندرك أن بحوث الكوارث في الخدمة الاجتماعية تستتد في المقام الأول إلى علم النفس وعلم الاجتماع، وتتفذ هذه البحوث في البيئات الإكلينيكية

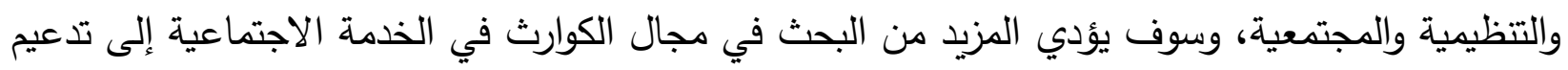
النظرية والقياس والممارسة، في مواقف الضغوط الجماعية (Zakour, 1997).

\section{مهنة الخدمة الاجتماعية والأزمات :}

أما من حيث التدخل المهني للخدمة الاجتماعية في الأزمات فقد استخدم التدخل في الأزمات بوصفه

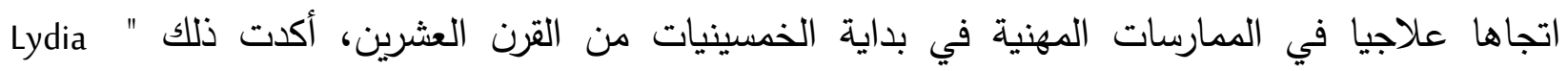
Rapoport1965 "في كتابها "حالة الأزمة: بعض الاعتبارات النظرية" حيث أشارت إلى أن الأخصائيين

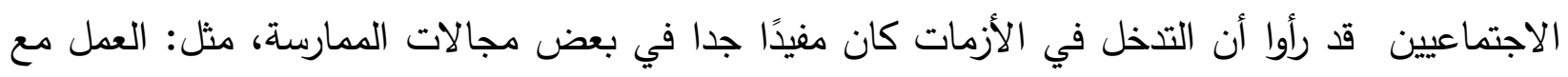
المسنين، وكذلك العمل مع ضحايا الاغتصاب، كذلك وجد الأخصائيون الاجتماعيون في مجال الرعاية الصحية، أن المدخل العلاجي يتماشى بشكل كبير مع طبيعة ممارساتهم المهنية.

وتبرز أهمية الاعتماد على التذخل في الأزمات في ممارسات الخدمة الاجتماعية في أنه في كثير من الأحيان قد تتسبب الأمراض والإصابات؛ في شعور المرضى وعائلاتهم، بمشاعر شديدة من العجز الإن

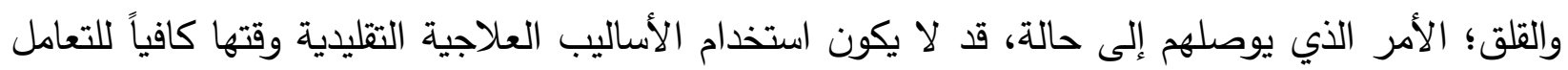

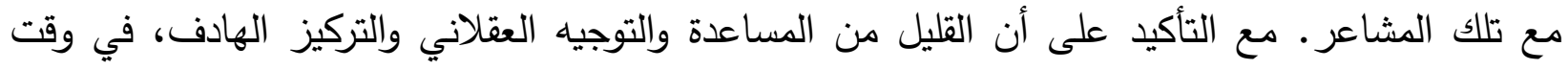
استراتيجي؛ يؤدى إلى جعل التدخل في الأزمات متوافقا مع الإطار الزمني المختصر ، المعتاد عليه، في ممارسة الخدمة الاجتماعية في المستشفيات (Rapoport, 1965, p. 30).

وبما أن الممارسات الوقائية تعد جزءا مهما من ممارسات مهنة الخدمة الاجتماعية ، فإن الخدمة

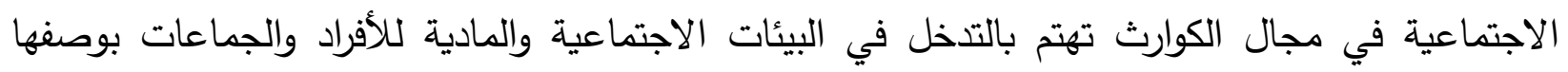
وسيلة لمنع حدوث مشكلات صحية ونفسية خطيرة وطويلة الأجل بعد الكارثة(Roge, 2003) • وتتجلى الوقاية بشكل كبير في التخفيف من حدة الكوارث في المجتمع، وقد يتضمن ذلك النشر السريع للمعلومات في شكل تعليمي عام؛ لحث السكان المستضعفين على الإخلاء عند سماع التحذير من الكوارث .ويشمل كذلك حثد 
الجماعات المجتمعية؛ لاعم مشاريع تخفيف آثار الكوارث على السكان، تلك المشاريع التي منها تطوير قوانين البناء لزيادة قدرة البيئة العمرانية على الصمود أمام الزلازل أو الفيضانات أو الرياح العاتية المرتبطة

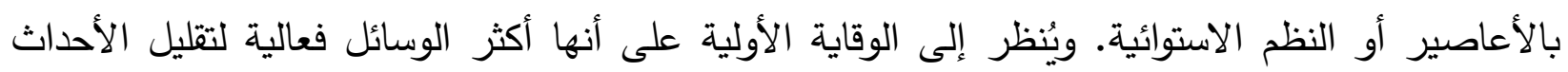
الصادمة في مخيمات اللاجئين (Drumm, et al., 2003).

كما تركز الممارسات الوقائية على التدخل في البيئات الاجتماعية والمادية للأفراد والجماعات بوصفها وسيلة لهنع حدوث المشكلات الصحية والعقلية الخطيرة طويلة الأجل بعد الكارثة، كما تتكون البيئة الاجتماعية المباشرة للأفراد من شبكات الدعم الاجتماعي، وتثمل ضمن ما تثمل العائلة والأصدقاء

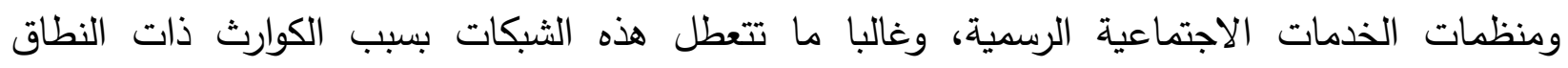
الإقليمي، وقد تسعى برامج الإغاثة من الكوارث إلى إعادة تشكيل شبكات الدعم لتقليل اضطرابات الأداء

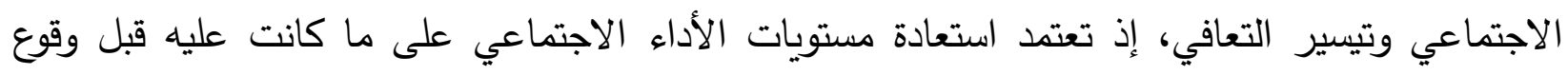

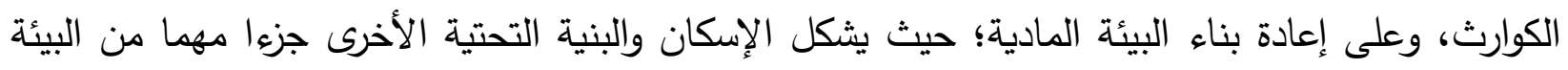
المادية للأفراد والأسر، وقد تتعرض هذه المباني والخدمات للتلف والتدمير بسبب الكوارث، ويمثل التدخل

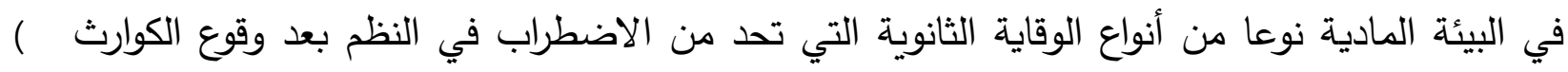
.Zakour, 2004, pp. 32-33).

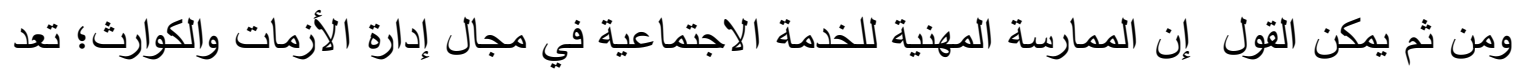
أحد أشكال الممارسة العصرية للمهنة، ولعل من الأسباب المهمة التي ساعدت على دخول مهنة الخدمة الاجتماعية هذا المجال، ظهور الاتجاهات الحديثة التي كانت - ولا تزال - تؤكد ضرورة إدارة الأزمات والكوارث بكافة أنواعها، حيث يتم تثكيل فرق عمل خاصة بذلك، تشمل كافة التخصصات، وأصبحت الحاجة التهات ماسة وضرورية، إلى وجود الأخصائي الاجتماعي ضمن هذه الفرق؛ نظرا لما تسببه هذه الأزمات والكوارث من مشكلات نفسية واجتماعية.

ومن أهم خصائص هذه المشكلات : الخوف، والتوتر، وفقدان الثقة بالنفس، وغيرها من المشكلات

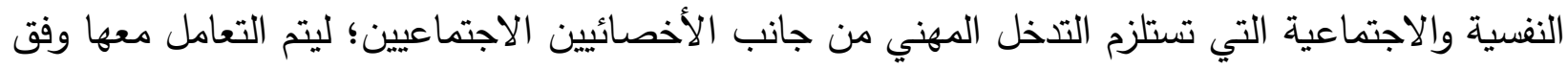

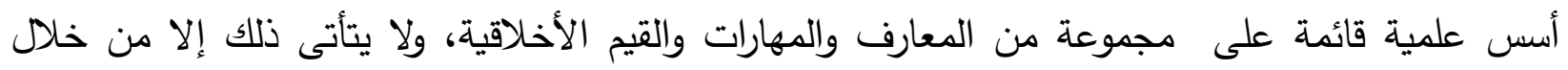
الاهتمام بالإعداد المهني للأخصائي الاجتماعي من قبل المؤسسات الأكاديمية المختصة بتعليم الخدمة الاجتماعية؛ حتى يكتسب المختص بالمعارف والمهارات المهنية الضرورية التي تؤهله لممارسة دوره بكفاءة واقتنار في هذا المجال. كما يجب أن نأخذ في الاعتبار أن المعرفة المتزايدة والمداخل المنظمة Systematic 
Approach السريع من خلال اندماج الممارسات العملية المهنية بالتعليم (Sherr,2008)

ومن وجهة نظرنا وجب التأكيد على التاريخ الطويل للجهود المهنية في تقديم الخدمات والمساعدات

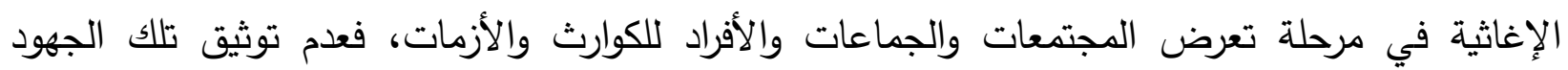

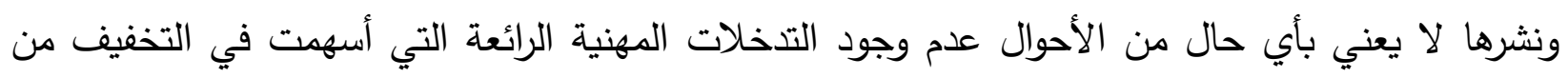

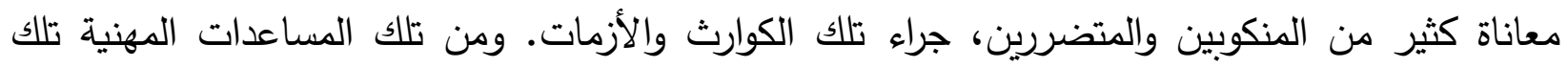

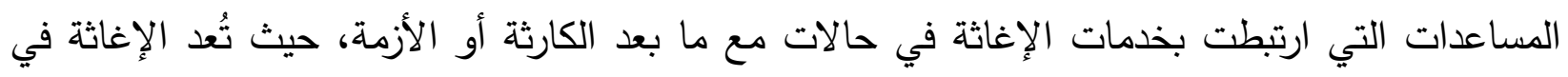

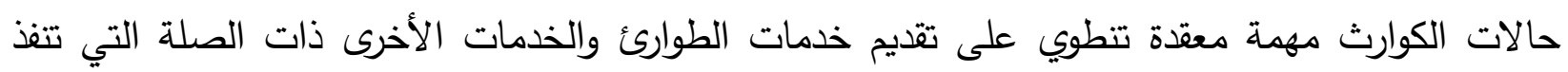
بواسطة الأخصائيين الاجتماعيين وعن طريقهم.

ومن ثم ينبغي الاعتراف بهذه النوعية من الخذمات بوصفها جزئًا من الممارسة المهنية للخدمة

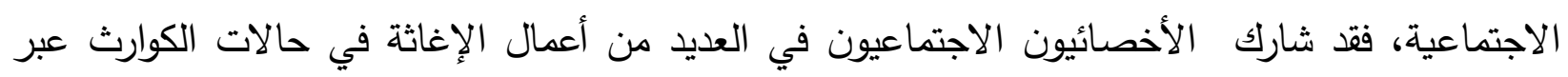

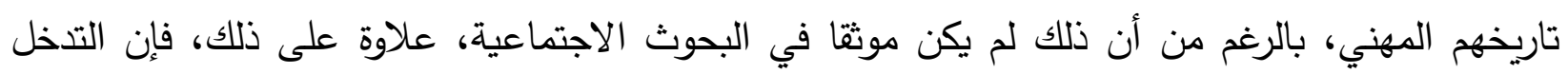

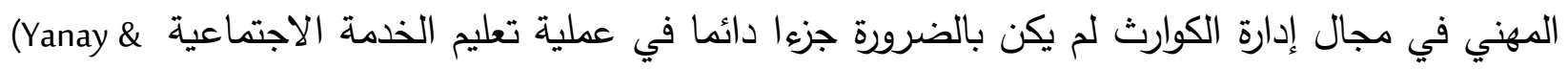

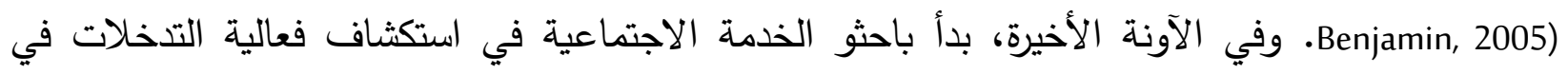

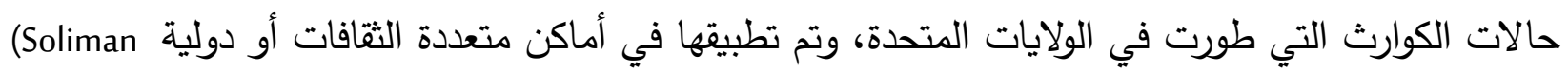
\& Paula, 2003).

وختاما يمكن التأكيد على الإسهامات الميزة التي يمكن أن تقدمها بحوث الكوارث في الخدمة

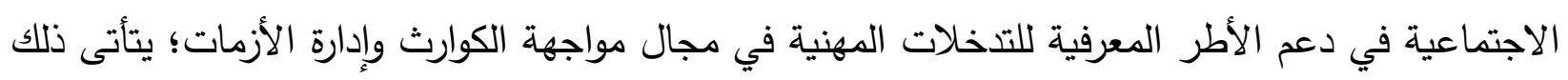

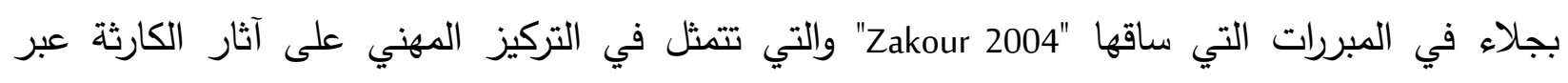

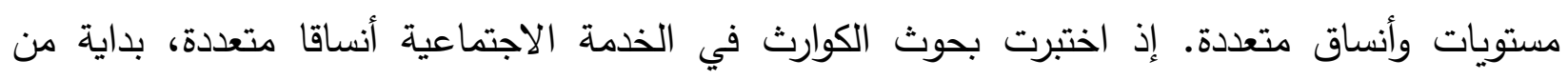

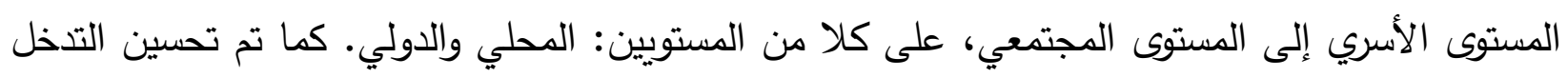

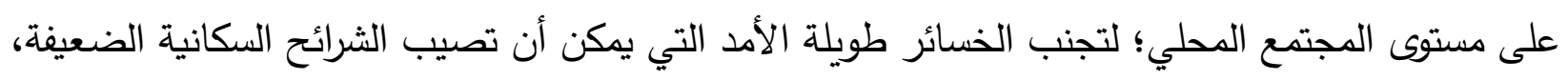

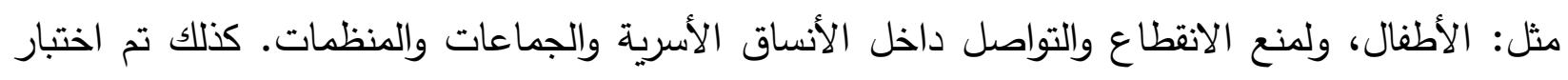

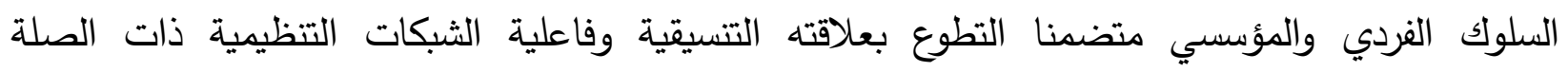

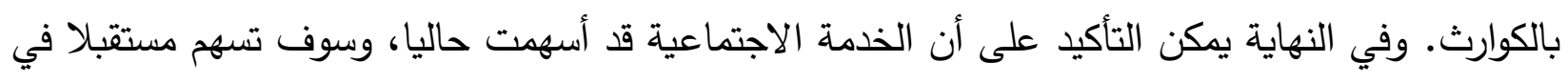

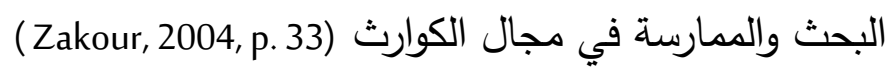


سابعا: مفهوم إدارة الكوارث ودورتها

تُعد إدارة الكوارث واحدة من العوامل الرئيسة التي تئثر على الوقاية من الكوارث، وتكون بمثابة

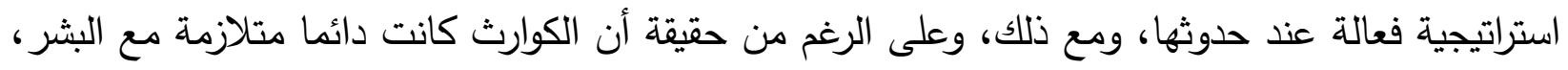
فلا تزال إدارة الكوارث بمثابة حقل مهني وعلمي جديد نسبيا (Asgary, 2006). ويعد مفهوم دورة إدارة "Disaster Management Cycle" لها، وتثمل كذلك أنثطة ما قبل الكوارث، مثل: الوقاية، والتخفيف، والتأهب، وأنشطة ما بعد الكوارث وتثمل: الاستجابة، والبحث، والإنقاذ، والإغاثة، وإعادة الإعمار ، وإعادة التأهيل، وقد يثير المفهوم إلى إدارة

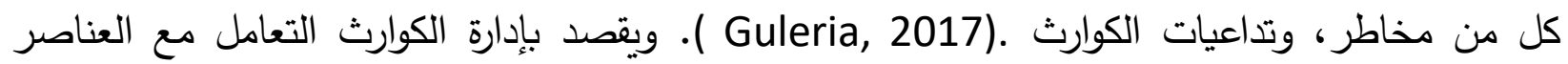
المكونة للكارثة، والأطراف الداخلة فيها؛ وبناء عليه يتطلب الوضع سرعة اتخاذ قرارات حاسمة في مواجهة الموقف الطارئ الذي أدت إليه الكارثة؛ ومن ثم تمارس إدارة الكوارث والأزمات في ظل متغيرات ثلاثة:

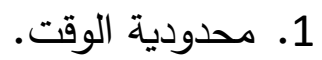

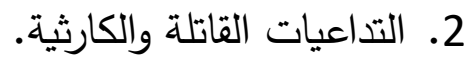

3. ندرة المعلومات، وعدم كفايتها ودقتها.

وبخصوص دورة الكارثة فيمكن تقسيمها إلى خمس مراحل رئيسية، تطول مدتها أو تقصر من كارثة إلى أخرى، والمراحل هي: مرحلة الإنذار التي تثير إلى احتمال وقوع كارثة وفترة التهديد التي تكون خلالها الكارثة معلقة، مرحلة التأثير عند وقوع الكارثة، مرحلة الطوارئ عندما تبدأ أنشطة الإنقاذ والعلاج، مرحلة الإني إعادة التأهيل عند تقديم الخدمات الأساسية على أساس مؤقت، مرحلة إعادة البناء عندما يتم تحقيق عودة البهاء دائمة إلى الحياة الطبيعية. وتختلف الوفيات والاعتلالات الصحية الناجمة عن الكوارث على مدار هذه المراحل، وهي أيضًا دالة على الظروف الصحية والاجتماعية والاقتصادية السائدة في المجتمع المتأثر بالكارثة. ونتيجة للاك تبدو أن الإحصاءات العالمية المتعلقة بالكوارث تثير إلى تواتر أكبر بكثير للكوارث الطبيعية في البلدان النامية عنها في الدول المتقدمة (Guha-Sapir \& Lechat, 1986)

ثامنا: القيم الأخلاقية للخدمة الاجتماعية أثناء الكوارث إن التعامل المهني المحترف مع المنكوبين والمتضررين من الكوارث يعد من الأمور التي تتسم بالحساسية المفرطة، حيث تتعدد جوانب التأثر التي يعاني منها هؤلاء المنكوبون، ومن جنابنا نري أن هذه

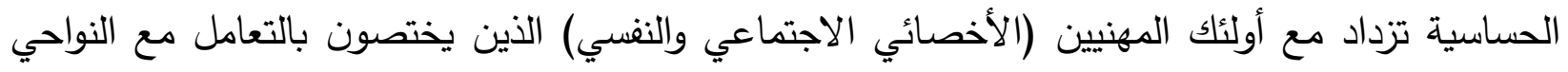

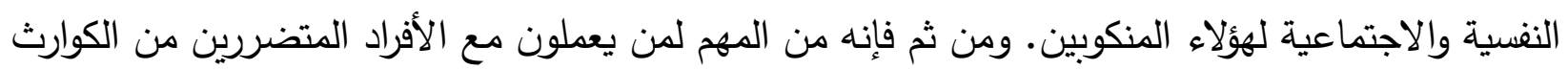


أن يفهموا الكيفية التي يتأثر بها الفرد من كافة النواحي، وهذا يعني أن الكارثة لا تؤثر فقط على عقل

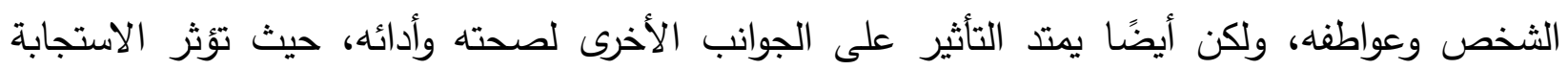
الإنسانية للكوارث في وقت واحد على ثلاثة أبعاد مختلفة ولكنها ذات صلة ببعضها تلك التي تتمثل في

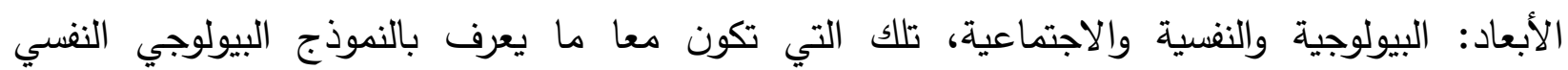
الاجتماعي(Bio-psycho-social model).

ويمكن تثبيه هذه الجوانب الثلاثة من الأداء البشري بالأرجل الثلاثة للمقعد ثلاثي السيقان، حيث تعد

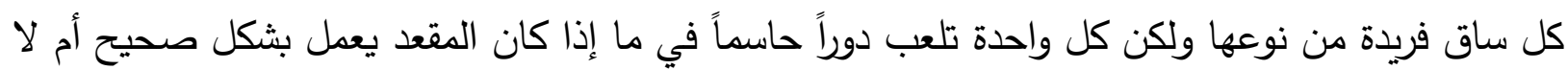
(Becker, et al., 2008, p. 6) ومن ثم فإن الالتزام الصارم بتطبيق القيم والمبادئ المهنية من جانب

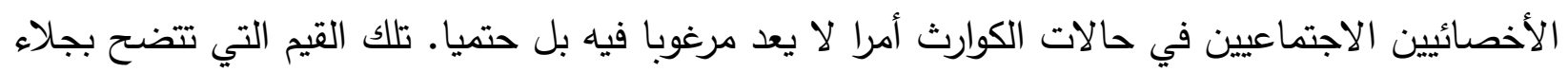
من خلال العديد من المواثيق الأخلاقية للمهنة في كافة الدول دون استثناء.

كما تتضح هذه القيم في المفهوم العالمي للخدمة الاجتماعية Global Definition of Social Work ذلك المفهوم الذي أكسبها أهمية خاصة بين كافة المهن المعترف بها محليا وعالميا، ذلك المفهوم

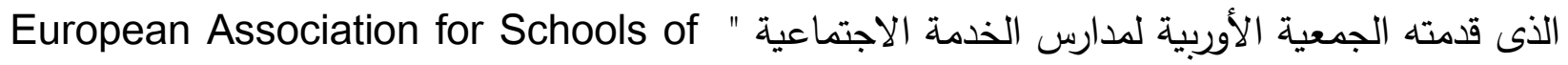
Social Work" والذي يؤكد أنها تلك المهنة القائمة أساسا على الممارسة وذلك التخصص الأكاديمي الذي الذي يعزز التغيير الاجتماعي والتتمية والتماسك الاجتماعي، وتمكين الناس وتحريرهم، ويقوم على مبادئ العدالة الاجتماعية، وحقوق الإنسان، والمسؤولية الجماعية، واحترام التتوع، مما يعد ركائز أساسية للخدمة الاجتماعية مدعومة بنظريات العمل الاجتماعي والعلوم الاجتماعية والإنسانية والمعرفة الأصلية (ثقافة (المجتمع).

وتقوم الخدمة الاجتماعية على أساس مشاركة الناس والمؤسسات في مواجهة تحديات الحياة وتعزيز رفاهية الإنسان. ويمكن تبني هذا المفهوم على المستويات العالمية أو الإقليمية (E A S S W, 2017). وقد تضمن هذا التعريف مجموعة من القيم والمبادئ الأخلاقية التي توجه الأخصائيين الاجتماعيين في الإني الإني أثناء الممارسة، تلك القيم التي تم الاعتراف بها واقعيا عام 2014، من قبل الاتحاد الدولي للأخصائيين الاجتماعيين، والرابطة الدولية لمدارس الخدمة الاجتماعية، وقد تم تبني هذا التعريف وتطبيقه على

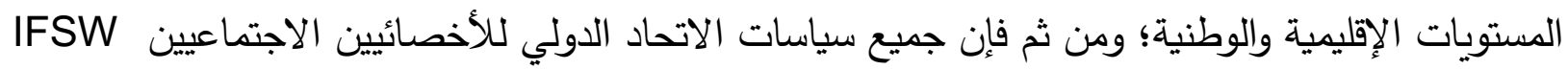
بما فيها من تعريف الخدمة الاجتماعية يصاغ في ضوء هذه المبادئ الأخلاقية (IFSW, 2018). 
ومن خلال التعريف العالمي للخدمة الاجتماعية، يمكن تحديد أهم محاور الممارسة المهنية في ثلاثة

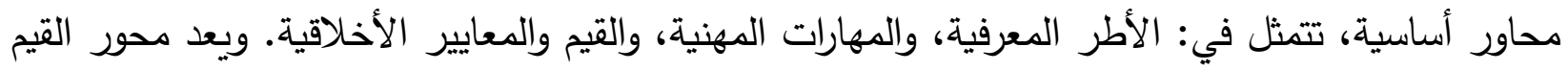
والمعايير الأخلاقية النواة الرئيسية للورقة الحالية؛ لذا سوف نركز على تلى تلاوله بثكل يوضح أهم القيم

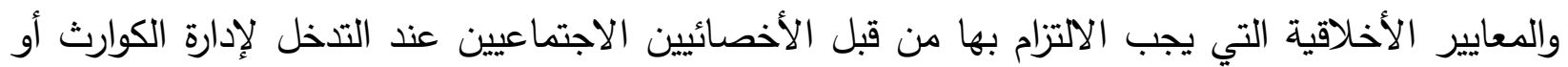

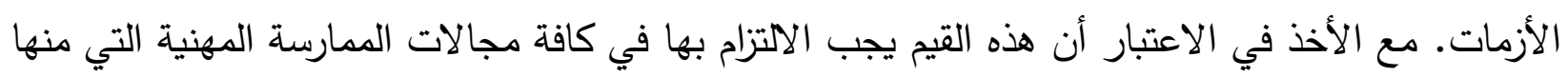

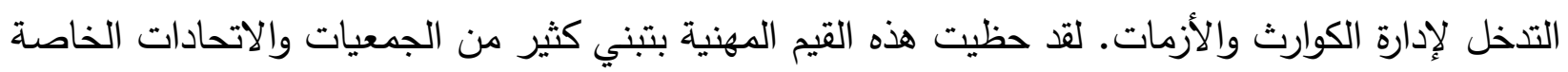

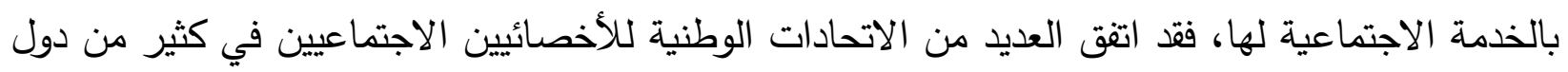

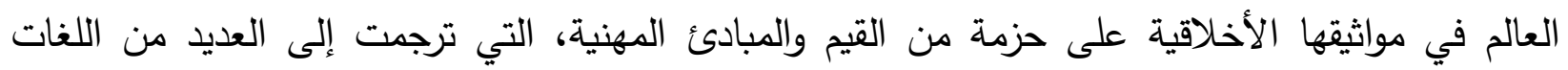
العالمية (IFSW, 2018)

وعلى الرغم من أنه لا يمكن حصر هذه القيم وعدها، فإن هنالك اتفاقا على مجموعة من القيم الأساسية لمهنة الخدمة الاجتماعية بداية من النزاهة إلى احترام كرامة الفرد وتقدير المشاعر والعدالة

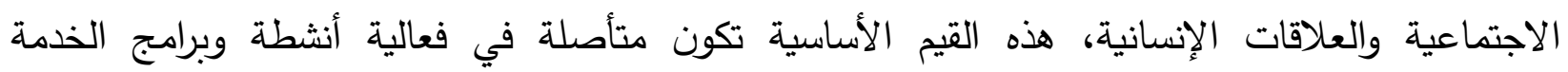
الاجتماعية، وتساعد في تحقيق أغراض مهنية محددة، على سبيل المثال: فإنها ترسخ الأساس الأخلاقي

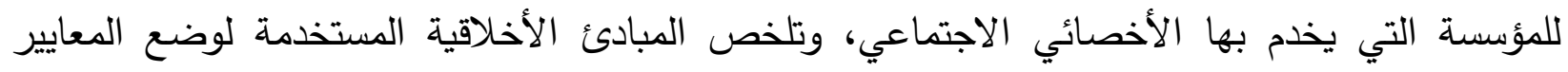

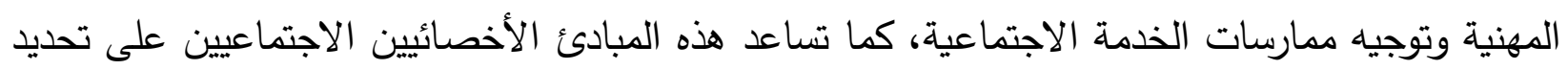
الالتزامات المهنية بما يضمن عدم تضارب المصالح القانونية.

كذلك تعد هذه المبادئ في حد ذاتها معايير عامة يمكن للجمهور استخدامها لمسألة الأخصائيين الاجتماعيين، وتتمثل القيم الخمسة الأكثر استحواذا على الاهتمام في برامج تعليم الخدمة الاجتماعية في:

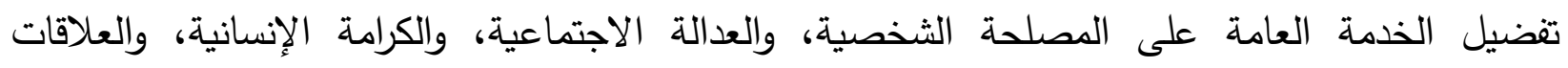
الإنسانية، والنزاهة (Social Work degree guide, 2020). ومن ثم يمارس الأخصائي الاجتماعي وظيفته في ولهي مجال الكوارث والأزمات بوصفه أحد مجالات الممارسة المهنية في نطاق قيم المهنة ومبادئها وأخلاقياتها. فالالتزام بهذه الأخلاقيات يسهم بلا شك في ترسيخ مكانة المهنة في مثل هذه الظروف، مع الأخذ في

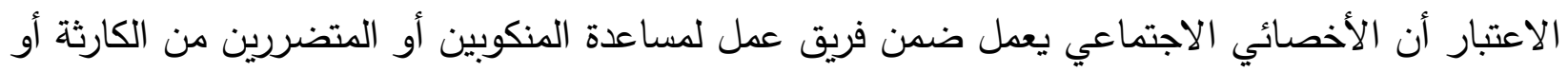

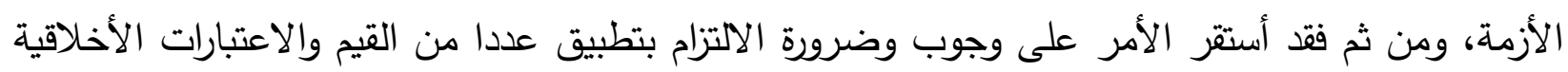
التي يجب مراعاتها في أثناء تقديم الخدمات في حالات الكوارث، من هذه القيم على سبيل المثال وليس الحصر : 


\section{الاحترام والكرامة المتأصلة في الإنسانية}

يدرك الأخصائيون الاجتماعيون الكرامة المتأصلة في جميع البشر، ويحترمونها في المواقف وبالكلمات وبالأفعال (IFSW, 2018)؛ لذا قد يجد العديد من الناجين من الكوارث الطبيعية والتكنولوجية صعوبة في طلب المساعدة من منظمات الخدمات بسبب الوصمة الاجتماعية المرتبطة بهذه الوكالات في كثير من الأحيان، والخوف من فقدان الاحترام، والاستقلال، والسيطرة على حياتهم، ومن ثم يجب على الأخصائيين الاجتماعيين تقييم أفضل الطرق لتسهيل التدخل في أثناء العلاقات المتبادلة مع المتضررين، والاحترام الكامل للأفراد والأسر في سياق التدخل بعد حدوث الكارثة، كما يلتزم الأخصائيون الاجتماعيون بالتزامات ما بعد الكوارث، من خلال إشرالك وسائل الإعلام بحكمة، وبطرائق تحمي حقوق الناجين.

\section{تعزيز الحق في تقرير المصير}

قد تؤدي الكوارث إلى خلق حالة من الارتباك وعدم اليقين والصراع، ومن هنا يجب أن يتخذ الناجون

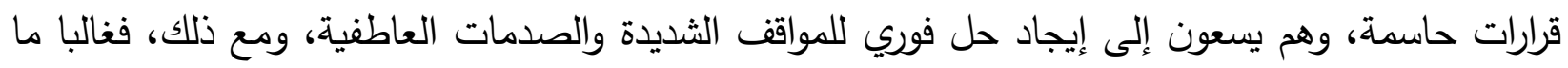
يتم تقييد الاستقلالية الفردية مع قيام منظمات الاستجابة للطوارئ بتنفيذ عمليات ما بعد الكوارث، حيث يكون

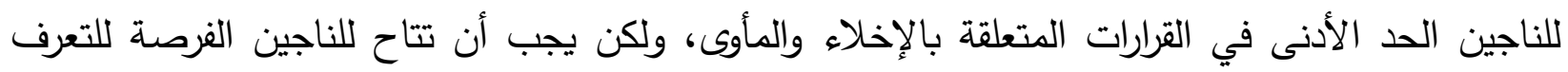
على أوضاعهم الفريدة من الحياة أو احتياجاتهم الخاصة، كما يجب على الأخصائيين الاجتماعيين توخي الحذر بعد الكارثة عند استخدام الأساليب التي تعزز من حق تقرير المصير للناجين سواء أكان ذلك في

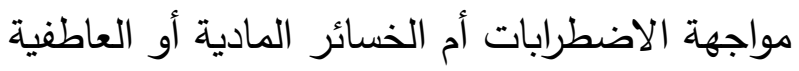

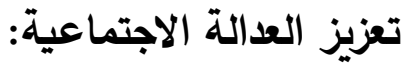

إن الأمن البدني والإعاشة ضروريان لجميع الأفراد والأسر والمجتمعات للتعافي من آثار الكوارث، فعند الاستجابة للكوارث والتعافي منها، تتصدى الثبكات الاجتماعية، والمتطوعون، والمنظمات غير الرسمية

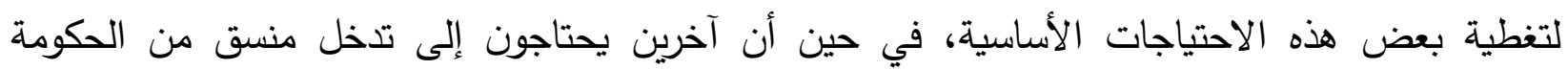

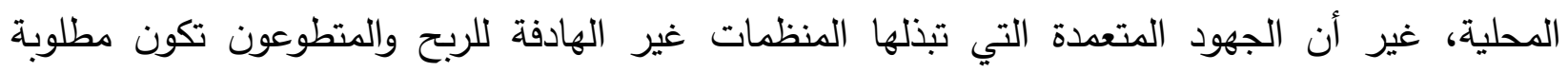

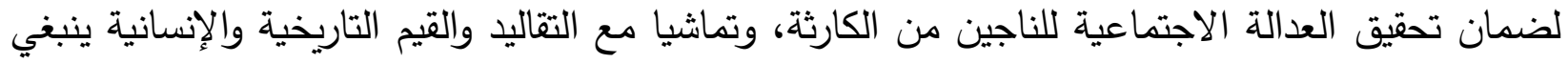
على الأخصائيين الاجتماعيين إيلاء اهتمام خاص باحتياجات السكان المعرضين والمحرومين في ظل ظروف الكوارث، بما في ذلك الأطفال والمسنين، والأشخاص الذين يعانون من إعاقات جسدية وعقلية، وعليه يجب على الأخصائيين الاجتماعيين أن يكونوا قادرين على تطبيق مبادئ العدالة التوزيعية، والإجرائية، والتشاركية، في ظل ظروف الكوارث (Suliman \& Rogge, 2002). 
وفي هذا الإطار حث الاتحاد الدولي للأخصائيين الاجتماعيين IFSW، الأخصائيين على تعزيز

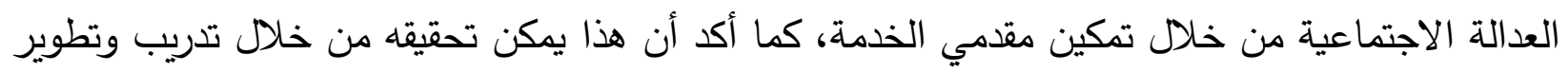

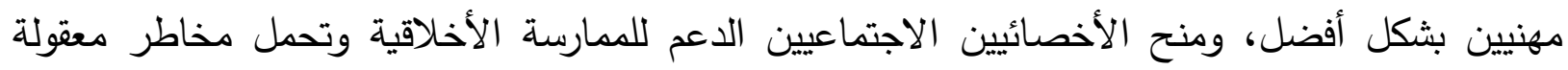

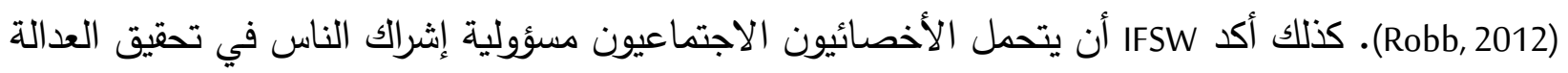

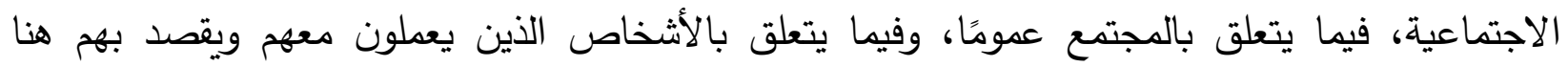

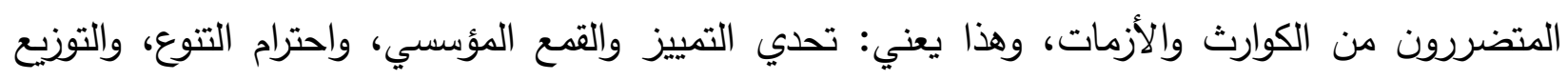
العادل للموارد والثروات، وتحدي الممارسات والسياسات غير العادلة، وبناء التضامن، (IFSW, 2018).

وقد سبق "Zakuor" "إلى تأكيد ذلك في إحدى مقالاته عن الذذمة الاجتماعية في مجال الكوارث،

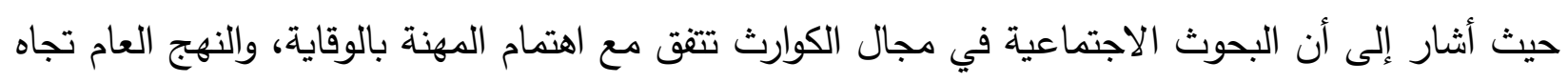

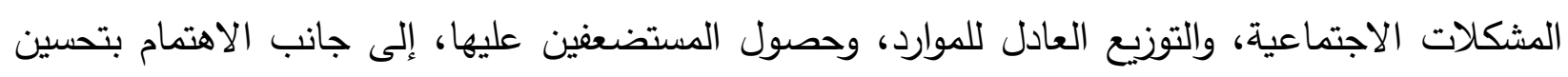
مستويات المساواة في تقديم الخدمات للمتضررين من هذه الكوارث . (Zakour, 2004)..

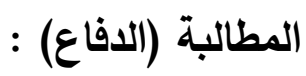

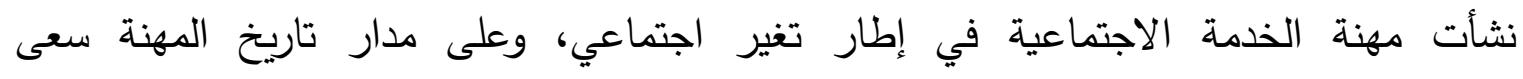

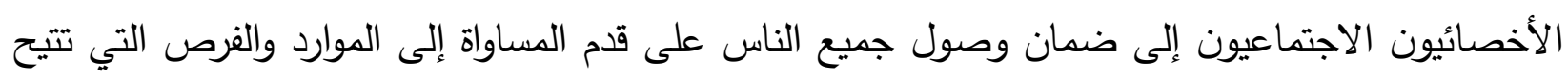

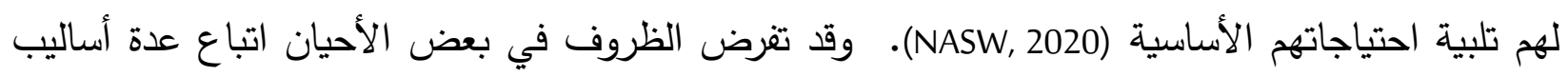

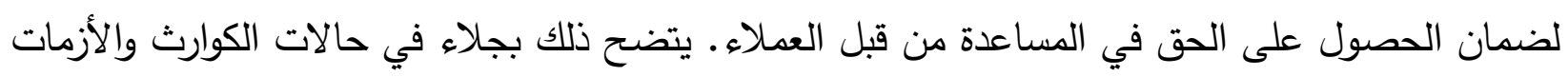

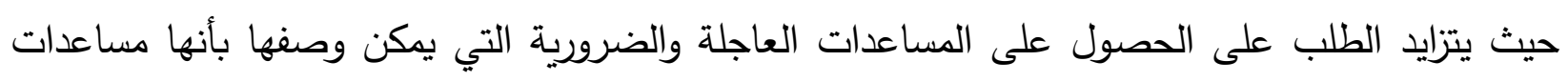

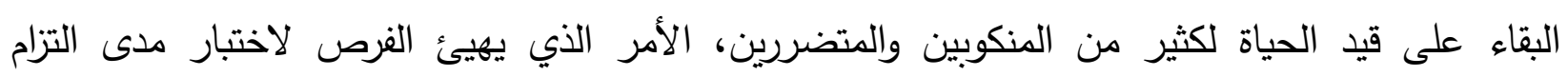
الأخصائيين الاجتماعيين بقيمهم المهنية.

وهنا تظهر الدافعة بوصفها واحدة من أكثر التضايا إثارة للجدل في الاستجابة للكوارث والتعافي

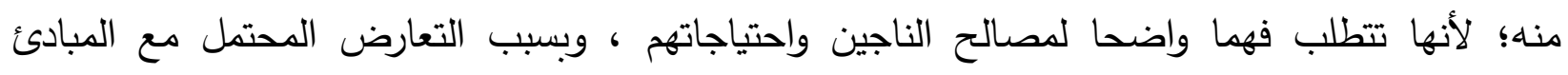

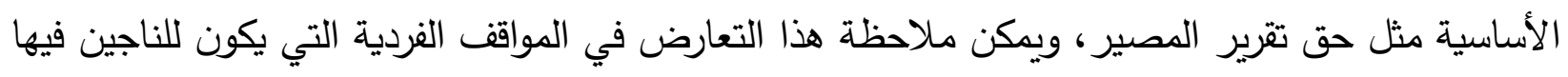

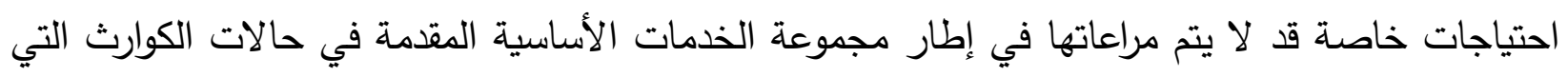

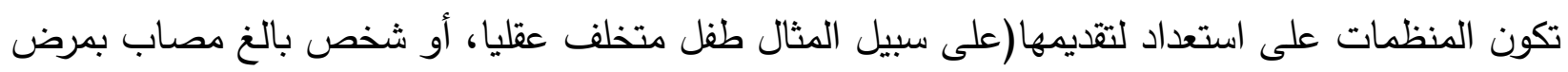
الزهايمر). 
وفي مثل هذه الحالات تكون الخدمة الاجتماعية ملزمة بتقييم الاحتياجات الثخصية للأفراد والأسر للحفاظ على أداء مستوى الكفاف، والمشاركة في الدفاع عن تلك القضايا لتلبية احتياجاتهم هؤلاء المتفردين

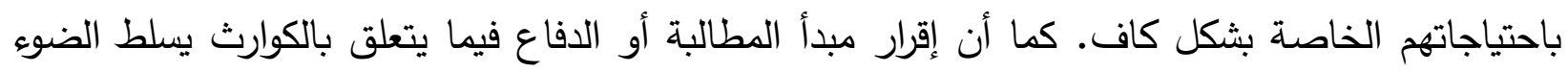
على التزام الأخصائيين الاجتماعيين بالاشتراك في عمليات التقييم والتخطيط والتأهب لما قبل الكارثة لزيادة احتمال توفر الخدمات لذوي الاحتياجات الخاصة متى ما وقعت الكارثة (Suliman \& Rogge, 2002)

خاتمة

سلط البحث الحالي الضوه على التتاول التاريخي للتنخل المهني للخدمة الاجتماعية في الكوارث، وكذلك تدخلها في الأزمات؛ حيث إن عددا غير قليل من الباحثين قد تتاولهما بوصفهما شيئا واحدا، والحقيقة

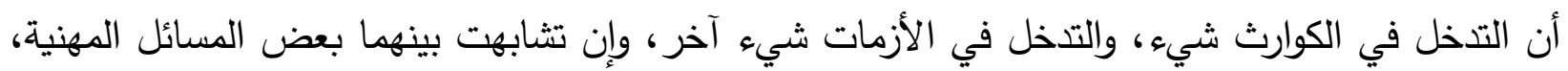
كالالتزام بالمبادئ والقيم والمعايير الأخلاقية من قبل الممارسين، في أثناء التدخل في أي منهما. ومن ثم كان التهات ذلك داعيا إلى التفريق بين مفهوم الكارثة وأنواعها، ومفهوم الأزمة، ومحاولة تبيان مدى الإنى الاختلاف بينهما. إن ما يمكن أن نستخلصه من هذه الخاتمة أن مهنة الخدمة الاجتماعية كان لها باع طويل من التتخل في الأزمات والكوارث؛ وأنه قد لوحظ اختلاف في الثواهد النظرية في التراثين الغربي والثرقي، حول توقيت بداية التدخل المهني في الكوارث والأزمات. فمن وجهة نظرنا وجب تأكيد التاريخ الطويل للجهود المهنية في تقديم الخدمات والمساعدات الإغاثية في مرحلة تعرض المجتمعات والجماعات والأفراد للكوارث والأزمات، إذ تأخر التظظير حول تدخل الخدمة الاجتماعية في الأدبيات الثرقية، لكن عدم توفر هذا التتظير حول دور الأخصائيين الاجتماعيين في مجال الكوارث في الدول الأسيوية والعربية لا يعنى انعدام الجهود المهنية في تلك البلدان، بقدر ما يعزى ذلك إلى افتقاد عنصر توثيق هذه الجهود ونشرها، ولا سيما في

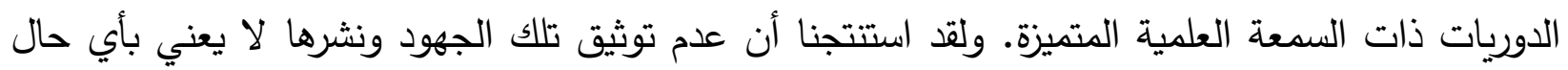
من الأحوال عدم وجود التذخلات المهنية الرائعة التي أسهمت في التخفيف من معاناة كثير من المنكوبين والمتضررين، جراء تلك الكوارث في العديد من المجتمعات، وخاصة الأسيوية.

كذلك تعرض البحث للإسهام التاريخي المتميز لمهنة الخدمة الاجتماعية في مجال الكوارث والأزمات على مستوى الممارسة، والتأكيد على تطور بحوث الكوارث في الخدمة الاجتماعية من خلال الدراسات الاجتماعية والنفسية للكوارث؛ ما نتج عنه توافق المفهوم المهني للكوارث والاهتمامات الرئيسة لبحوث الكوارث في الخدمة الاجتماعية مع الرؤى النظرية للمهنة، ومهمتها التاريخية. 
إضافة إلى ما سبق فقد أكد البحث الحالي دور بحوث الكوارث في الخدمة الاجتماعية في دعم الأطر المعرفية للتدخلات المهنية في مجال مواجهة الكوارث وإدارة الأزمات، ذلك الدور الذي أدى إلى ظهور الاتجاهات الحديثة في الخدمة الاجتماعية التي كانت - ولا تزال - تؤكد ضرورة التدخل للمشاركة في إدارة الكوارث بكافة أنواعها. كما كان الهدف من تتاول التأثيرات السلبية للكوارث - بشكل عام - هو توضيح دور التدخل المهني في إعادة إصلاح العطب الذي لحق بشبكات الدعم الاجتماعي غير الرسمية بالمجتمعات

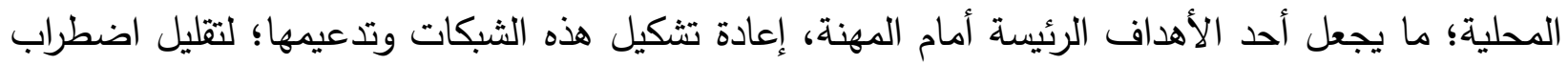
الأداء الاجتماعي، وتيسير التعافي لدى المنكوبين المتضررين من الكارثة. وأخيرا كان التركيز على محور القيم المهنية - التي يفترض أن يسترشد بها الأخصائيون الاجتماعيون - أمرا مهما لتوضيح مدى الحاجة إلى مراعاة القدر الأكبر من الحساسية عند التطبيق، حيث يكون المنكوبون والمتضررون من الكارثة في أمس الحاجة إلى الدعم النفسي والاجتماعي الذي يوفر لهم القدر الأكبر من مراعاة المشاعر التي تملكتهم جراء حدوث الكارثة، وتقديرها فيجب ان يدرك الهون الأخصائيون

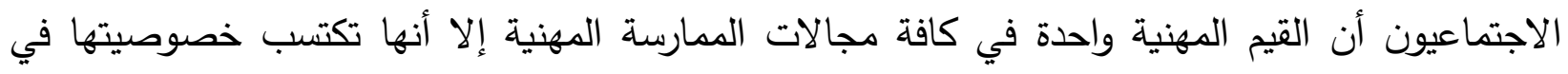
مجال إدارة الكوارث؛ نظرا لطبيعة وخصوصية الظرف الكارثي؛ فلابد أن يراعي الأخصائيون - بدرجة

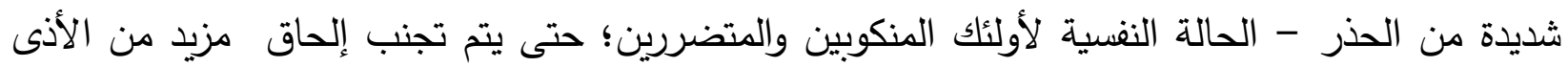
النفسي أو الاجتماعي أو المادي بهم، بالإضافة إلى أن هذا الالتزام القيمي يسهر - دون شك ولك - في زيادة

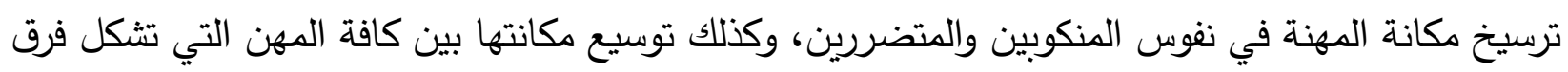
العمل للتدخل في الكوارث والأزمات

\section{References}

Guleria, S., 2017. TRAINING OF TRAINERS' PROGRAMME ON BASICS OF DISASTER MANAGEMENT, NIDM- South Campus: s.n.

Sherr, M. L., 2008. Social Work With Volunteers. Chicago. Nonprofit and Voluntary Sector Quarterly, 21 October, 38(5), pp. 910-913.

Zakour, M. J., 2004. SOCIAL WORK AND DISASTERS. [Online] Available at:

https://training.fema.gov/emiweb/downloads/edu/socialworkanddisasters4.doc [Accessed 23 January 2020]. 
Asgary, A., 2006. Theorizing disaster and emergency management. In: C. Raj Kumar \& D.K. Srivastava, eds. Tsunami and disaster management: Law and governance. Hong Kong: Thomson, p. 42.

Becker, K., Sapirstein, G. \& Weir, J., 2008. Psychological support for survivors of disaster A practical guide, s.I.: IBM International Foundation .

Drumm, R. D., Sharon , P. W. \& Perr, S., 2003. Social Work Interventions in Refugee Camps: An Ecosystems Approach. Journal of Social Service Research, 30(2), pp. 67-92.

E A S S W, 2017. Global definition of Social Work. [Online] Available at: https://www.eassw.org/language/english/ [Accessed 1 March 2019].

EMDAT, 2019. OFDA/CRED International Disaster Database, Brussels- Belgium: Université catholique de Louvain.

European Association for Schools of Social Work, 2017. Global definition of Social Work. [Online]

Available at: https://www.eassw.org/language/english/ [Accessed 1 March 2019].

Grossman, L., 1973. Train crash: social work and disaster services. Social Work, September, 18(5), pp. 38-44.

Guha-Sapir, D. \& Lechat, M., 1986. The Impact of Natural Disasters: A Brief Analysis of Characteristics and Trends. Prehospital and Disaster Medicine, 2(1-4), pp. 221-223.

IFRC, 2020. Types of disasters: Definition of hazard. [Online] [Accessed 26 January 2020].

IFSW, 2018. Global Social Work Statement of Ethical Principles. [Online] Available at: https://www.ifsw.org/global-social-work-statement-of-ethicalprinciples/

[Accessed 27 January 2020].

Jaworowski, Z., 2010. Observations on the Chernobyl Disaster and LNT. Doseresponse. International Hormesis Society,, 8(2), pp. 148-171. 
Masson, V. L., Lim, S., Budimir, M. \& Poddoj, J. S., 2016. Disasters and violence against women and girls: Can disasters shake social norms and power relations?. UK, Overseas Development Institute, pp. 1-22.

NASW, 2020. Advocacy. [Online]

Available at: https://www.socialworkers.org/Advocacy [Accessed 28 January 2020].

Nikku, B. R., 2015. Living through and responding to disaster: Multiple roles for Social Work. The International Journal of Social WorK Education, 34(6), pp. 601606.

Nojavan, M., Salehi, E. \& Omidvar, B., 2018. Conceptual change of disaster management models: A thematic analysis., Jàmbá: Journal of Disaster Risk Studies, 10(1).

O'Hagan , K., 2005. Crisis Intervention in Social Work. In: J. Lishman, ed. Handbook of Theory for practice Teachers in Social Work. 10 ed. s.I.:Londom and Phladelpia.

Rapoport, L., 1965. The State of Crisis: Some Theoretical Considerations. In: Crisis Intervention: Selected Readings. New York: Family Service Association of America. Ritchie , H. \& Roser , M., 2020. Natural Disasters. Our World in Data. Robb, 2012. Give social workers a role in disaster relief work. England, Britsh Association of socail work.

Rogge, M. E., 2003. The Future is Now: Social Work, Disaster Management, and Traumatic Stress in the 21st Century. Journal of Social Service Research, 30(2), pp. $1-6$.

Sands, R. G., Fall 1983. Crisis Intervention and Social Work Practice in Hospitals. Health \& Social Work, 1 October, 8(4), p. 253-261.

Social Work degree guide, 2020. 5 of the Most Important Core Social Work Values. [Online]

Available at: https://www.socialworkdegreeguide.com/lists/5-important-coresocial-work-values/ [Accessed 27 January 2020].

Soliman, H. H. \& Paula, S. T., 2003. Preface. Journal of Social Service Research, 30(2), pp. xiii-xv.. 
Suliman, H. H. \& Rogge, M. E., 2002. Ethical Consideration in Disaster Services: Asocial Work Perspective. Electronic Journal of Social Work ISSN.

Tan, N. T. \& Rowlands, A., 2007. Asian tsunami and social work practice: Recovery and rebuilding. New York,: Routledge Press.

Yanay, U. \& Benjamin, S., 2005. The role of social workers in disasters: The Jerusalem experience. Sage Publications, pp. 1-14.

Zakour, M. J., 1996. Geographic and Social Distance during Emergencies: A Path Model of Interorganizational Links. Social Work Research , 20(1), pp. 19-29.

Zakour, M. J., 1997. Disaster Research in Social Work. Journal of Social Service Research, 22(1-2), pp. 7-25. 